\title{
Solving Problems with GCMs: General Circulation Models and Their Role in the Climate Modeling Hierarchy
}

\author{
Michael Ghil and Andrew W. Robertson \\ Department of Atmospheric Sciences \& Institute of Geophysics and Planetary Physics \\ University of California at Los Angeles, Los Angeles, California 90095-1565
}

\author{
Revised version
}

April 28, 1999

In General Circulation Model Development: Past, Present, and Future (Arakawa Festschrift), D. Randall (Ed.), Academic Press, sub judice. 


\begin{abstract}
We outline the familiar concept of a hierarchy of models for solving problems in climate dynamics. General circulation models (GCMs) occupy a special position at the apex of this hierarchy, and provide the main link between basic concepts—-best captured by very simple, "toy" models - and the incomplete and inaccurate observations of climate variability in space and time. We illustrate this role of GCMs in addressing the problems of climate variability on three time scales: intraseasonal, seasonal-to-interannual, and interdecadal. The problems involved require the use of atmospheric, oceanic, and coupled ocean-atmosphere GCMs. We emphasize the role of dynamical systems theory in communicating between the rungs of the modeling hierarchy — toy models, intermediate ones, and GCMs - and between modeling results and observations.
\end{abstract}


I. Introduction: the modeling hierarchy 4

A. Atmospheric modeling 4

B. Ocean and coupled modeling $\quad 8$

C. Dynamical systems theory 9

II. Intraseasonal oscillations, their theory and simulation 11

A. Extratropical oscillations: observations and theory 12

B. GCM simulations and their validation 14

III. El Niño-Southern Oscillation, from the Devil's Staircase to prediction 16

A. ENSO's regularity and irregularity 16

B. The Devil's Staircase across the modeling hierarchy 18

C. Regularity and prediction 22

IV. Interdecadal oscillations in the oceans' thermohaline circulation 24

A. Theory and simple models 24

B. Bifurcation diagrams for GCMs 27

$\begin{array}{ll}\text { V. Perspectives } & 28\end{array}$

References $\quad 30$

$\begin{array}{ll}\text { Tables } & 42\end{array}$

$\begin{array}{ll}\text { Figure captions } & 44\end{array}$ 


\section{Introduction: the modeling hierarchy}

A view of climate dynamics as a modern scientific discipline first emerged about 40 years ago (Pfeffer, 1960). We understand it at this end of the century as studying the variability of the atmosphere-ocean-cryosphere-biosphere-lithosphere system on time scales longer than the life span of individual weather systems and shorter than the age of our planet. When defined in these broad terms, the variability of the climate system is characterized by a power spectrum that has (i) a "warm-colored" broad-band component, with power increasing from high to low frequencies, (ii) a line component associated with purely periodic forcing, annual and diurnal, and (iii) a number of broad peaks that might arise from less purely periodic forcing (e.g., orbital change or solar variability), internal oscillations, or a combination of the two (Mitchell, 1976; Ghil and Childress, 1987, Ch. 11).

Understanding the climatic mechanism or mechanisms that give rise to a particular broad peak or set of peaks represents a fundamental problem of climate dynamics. The regularities are of interest in and of themselves, for the order they create in our sparse and inaccurate observations; they also facilitate prediction for time intervals comparable to the periods associated with the given regularity (Ghil and Childress, 1987, Sec. 12.6; Ghil and Jiang, 1998).

The climate system is highly complex, its main subsystems have very different characteristic times, and the specific phenomena involved in each one of the climate problems defined in the preceding paragraph are quite diverse. It is inconceivable, therefore, that a single model could successfully be used to incorporate all the subsystems, capture all the phenomena, and solve all the problems. Hence the concept of a hierarchy of climate models, from the simple to the complex, has been developed about a quarter of a century ago (Schneider and Dickinson, 1974).

\section{A. Atmospheric modeling}

At present, the best-developed hierarchy is for atmospheric models; we summarize this hierarchy following Ghil (1995). The first rung is formed by zero-dimensional (0-D) models, 
where the number of dimensions, from zero to three, refers to the number of independent space variables used to describe the model domain, i.e. to physical-space dimensions. Such 0-D models essentially attempt to follow the evolution of global surface-air temperature $\bar{T}$ as a result of changes in global radiative balance (Crafoord and Källén, 1978; Ghil and Childress, 1987, Sec. 10.2):

$c \frac{d \bar{T}}{d t}=R_{\mathrm{i}}-R_{\mathrm{o}}$

$R_{\mathrm{i}}=\mu Q_{0}\{1-\alpha(\bar{T})\}, \quad R_{\mathrm{o}}=\sigma m(\bar{T}) \bar{T}^{4}$.

Here $R_{\mathrm{i}}$ and $R_{\mathrm{o}}$ are incoming solar radiation and outgoing terrestrial radiation, while $c$ is the heat capacity of the global atmosphere, plus that of the global ocean or some fraction thereof, depending on the time scale of interest: one might only include in $c$ the ocean mixed layer when interested in subannual time scales but the entire ocean when studying paleoclimate; $d \bar{T} / d t$ is the rate of change of $\bar{T}$ with time $t, Q_{0}$ is the solar radiation received at the top of the atmosphere, $\sigma$ is the Stefan-Boltzmann constant, and $\mu$ is an insolation parameter, equal to unity for present-day conditions. To have a closed, self-consistent model, the planetary reflectivity or albedo $\alpha$ and greyness factor $m$ have to be expressed as functions of $\bar{T} ; m=1$ for a perfectly black body and $0<m<1$ for a grey body like planet Earth.

There are two kinds of one-dimensional (1-D) atmospheric models, for which the single spatial variable is latitude or height, respectively. The former are so-called energy-balance models (EBMs: Budyko, 1969; Sellers, 1969), which consider the generalization of the model (1) for the evolution of surface-air temperature $T=T(x, t)$, say,

$$
c(x) \frac{\partial T}{\partial t}=R_{\mathrm{i}}-R_{\mathrm{o}}+D
$$


Here the terms on the right-hand side can be functions of the meridional coordinate $x$ (latitude, co-latitude, or sine of latitude), as well as of time $t$ and temperature $T$. The horizontal heatflux term $D$ expresses heat exchange between latitude belts; it typically contains first and second partial derivatives of $T$ with respect to $x$. Hence the rate of change of local temperature $T$ with respect to time also becomes a partial derivative, $\partial T / \partial t$.

The first striking results of theoretical climate dynamics were obtained in showing that slightly different forms of Eq. (2) could have two stable steady-state solutions, depending on the value of the insolation parameter $\mu$ [see Eq. (1.1b)] (Held and Suarez, 1974; Ghil, 1976; North et al., 1981). In its simplest form, this multiplicity of stable steady states, or physically possible "climates" of our planet, can be explained in the 0-D model (1.1) by the fact that-for a fairly broad range of $\mu$-values around $\mu=1.0$ - the curves for $R_{\mathrm{i}}$ and $R_{\mathrm{o}}$ as a function of $\bar{T}$ intersect in 3 points. One of these corresponds to the present climate (highest $\bar{T}$-value), and another one to an ice-covered planet (lowest $\bar{T}$-value); both of these are stable, while the third one (intermediate $\bar{T}$ value) is unstable. To obtain this result, it suffices to assume that $\alpha=\alpha(\bar{T})$ is a piecewise-linear function of $\bar{T}$, with high albedo at low temperature, due to the presence of snow and ice, and low albedo at high $\bar{T}$, due to their absence, while $m=m(\bar{T})$ is a smooth, increasing function of $\bar{T}$ that attempts to capture in its simplest from the "greenhouse effect" of trace gases and water vapor (Ghil and Childress, 1987, Ch. 10).

The 1-D atmospheric models in which the details of radiative equilibrium are investigated with respect to a height coordinate $z$ (geometric height, pressure, etc.) are often called radiativeconvective models (Manabe and Strickler, 1964; Ramanathan and Coakley, 1978; Charlock and Sellers, 1980), since convection plays a key role in vertical heat transfer. While these models preceded historically EBMs as rungs on the modeling hierarchy, it was only recently shown that they, too, can exhibit multiple equilibria (Li et al., 1997; Rennó, 1997). The word (stable) "equilibrium," here and in the rest of this chapter, refers simply to a (stable) steady state of the model, rather than to true thermodynamic equilibrium. 
Two-dimensional (2-D) atmospheric models are also of two kinds, according to the third space coordinate which is not explicitly included. Models that resolve explicitly two horizontal coordinates, on the sphere or on a plane tangent to it, tend to emphasize the study of the dynamics of large-scale atmospheric motions (see Sec. II below), whether they have a single layer (Charney and DeVore, 1979; Legras and Ghil, 1985) or two (Lorenz, 1963b; Reinhold and Pierrehumbert, 1982). Those that resolve explicitly a meridional coordinate and height are essentially combinations of EBMs and radiative-convective models and emphasize therewith the thermodynamic state of the system, rather than its dynamics (Saltzman and Vernekar, 1972; MacCracken and Ghan, 1988; Gallée et al., 1991). Yet another class of "horizontal" 2-D models is the extension of EBMs to resolve zonal, as well as meridional surface features, in particular land-sea contrasts (Adem, 1970; North et al., 1983; Chen and Ghil, 1996).

Additional types of 1-D and 2-D atmospheric models are discussed and references to these and to the types discussed above are given by Schneider and Dickinson (1974) and Ghil (1995), along with some of their main applications. Finally, to encompass and resolve the main atmospheric phenomena with respect to all three spatial coordinates, general circulation models (GCMs) occupy the pinnacle of the modeling hierarchy. Their genesis and the special role of successive generations of UCLA GCMs in the development and application of atmospheric GCMs to climate problems in general are covered elsewhere in this volume in great detail. Rather than dwell on this history in the present chapter, we proceed to outline, even more succinctly, the modeling hierarchies that have grown over the last quarter-century in ocean and coupled ocean-atmosphere modeling.

Before doing so, it is worth noting that the results of climate simulations with GCMs, whether atmospheric or coupled, are often still interpreted in terms of the understanding gained from 0-D or 1-D EBMs. Wetherald and Manabe (1975), using a simplified sectorial GCM, confirmed the dependence of mean zonal temperature on the insolation parameter $\mu$ (the normalized "solar constant") obtained for 1-D EBMs by various authors. In fact, the sensitivity $\left.(d \bar{T} / d \mu)\right|_{\mu=1.0}$ of global temperature $\bar{T}$ to changes in $\mu$ near the present-day climate equals about $1 \mathrm{~K}$ per $1 \%$ change in the insolation for both EBMs and GCMs. Many GCM studies of climate-change 
response to increases in greenhouse trace-gas concentrations use actually a linearized version of Eq. $(1.1)$

$c \frac{d T}{d t}=-\lambda T+Q$

$\lambda=\sum_{i=1}^{I} \lambda_{i}, \quad Q=\sum_{j=1}^{J} Q_{j}$

for interpreting the roles of the different feedbacks $\lambda_{i}$, positive $\left(\lambda_{i}<0\right)$ or negative $\left(\lambda_{i}>0\right)$, and heat sources, $Q_{j}>0$, or sinks, $Q_{j}<0$ (e.g., Schlesinger and Mitchell, 1987; Cess, Potter, et al., 1989; Li and Le Treut, 1992).

\section{B. Ocean and coupled modeling}

The simplest 0-D ocean models are so-called box models, used to study the stability of the oceans' thermohaline circulation (Stommel, 1961; see Sec. IV below) or biogeochemical cycles (Sarmiento and Toggweiler, 1984; Keir, 1988; Paillard et al., 1993). There are 1-D models that consider the vertical structure of the upper ocean, whether the oceanic mixed layer only (Kraus and Turner, 1967; Karaça and Müller, 1989) or the entire thermocline structure.

For the oceans, 2-D models also fall into the two broad categories of "horizontal" and "vertical." Models which resolve two horizontal coordinates emphasize the study of the oceans' wind-driven circulation (Cessi and Ierley, 1995; Jiang et al., 1995c; Berloff and Meacham, 1997), while those that consider a meridional section concentrate on the overturning thermohaline circulation (THC: Quon and Ghil, 1992, 1995; Thual and McWilliams, 1992). The wind-driven circulation is involved most strongly in sub- and interannual climate variability, while changes in the THC affect most strongly climate variability on the decade-to-century time scale and longer. Still, the circulation in a predominantly horizontal or vertical plane has to affect the same water masses, and 3-D ocean GCMs are thus indispensable in understanding oceanic variability (McWilliams, 1996). 
Bryan and Cox's (1967) model has played a role for the development and applications of such models that resembles the one played by the UCLA GCM (e.g., Arakawa and Lamb, 1977) for atmospheric ones. A number of simplified versions of this ocean GCM (Bryan, 1986; Chen and Ghil, 1995) have been used in exploratory studies of multiple equilibria and self-sustained oscillations in the THC, in a spirit that resembles the use of a simplified atmospheric GCM by Wetherald and Manabe (1975) to complement EBM results on multiple climate equilibria.

A fairly well developed hierarchy of coupled ocean-atmosphere models has been applied to the problem of seasonal-to-interannual variability in the tropical Pacific ocean (Neelin et al., 1994; see Sec. III below). Its most important rungs are, in ascending order: essentially 0-D simple models, like the delay-oscillator model of Suarez and Schopf (1988); essentially 1-D intermediate coupled models (Cane and Zebiak, 1985; Jin et al., 1994); essentially 3-D hybrid coupled models, in which an ocean GCM is coupled to a much simpler, diagnostic atmospheric model (Neelin, 1990; Barnett et al., 1993); and fully coupled GCMs (Neelin et al., 1992; Robertson et al., 1995a, b). Recently, hybrid models of this type have also been applied to climate variability for the midlatitude (Weng and Neelin, 1998) and global (Chen and Ghil, 1996; Wang et al., 1999) coupled system.

\section{Dynamical systems theory}

It has become fairly commonplace to state that the climate system contains numerous nonlinear processes and feedbacks, and that its behavior is rather irregular, but not totally random. Dynamical systems theory studies the common features of nonlinear systems of differential equations, ordinary (Smale, 1967) and partial (Constantin et al., 1989). The work of Lorenz (1963a, 1964) has played a key role in establishing the relevance of this theory to studying climate variability, as well as in advancing the theory itself.

This theory can be used systematically to explore robust features of climate-system behavior on a given time scale—intraseasonal, seasonal-to-interannual, and interdecadal—as we move up and down the rungs of the modeling hierarchy for the given problem, and from the models to the relevant observations. The main features of dynamical systems theory that are important for 
the study of climate have been summarized by Ghil et al. (1991a); they involve essentially bifurcation theory (Guckenheimer and Holmes, 1983) and the ergodic theory of dynamical systems (Eckmann and Ruelle, 1985).

Bifurcation theory permits one to follow-through successive bifurcations, computed analytically or numerically_climatic behavior from the simplest kind of model solutions to the most complex, from single equilibria through multiple ones and on to periodic, chaotic and fully turbulent solutions. Bifurcations can be computed analytically only for steady states (fixed points in the language of the theory) and periodic solutions (limit cycles in the same language), and for relatively simple models (Charney and DeVore, 1979; North et al., 1981; Jin and Ghil, 1990). Transitions to more complicated behavior, quasi-periodic, chaotic, or fully turbulent, need to be investigated numerically. Furthermore, even transitions to multiple equilibria or to periodic solutions need to be computed numerically in more detailed, realistic models (Ghil, 1976; Legras and Ghil, 1985; Strong et al., 1995).

The ergodic theory of dynamical systems provides statistical models for deterministically chaotic, as well as stochastically perturbed, climate evolution in space and time. This kind of nonlinear statistics permits one to evaluate systematically to which extent the behavior of fairly complex climate-model solutions matches that obtained with simpler, more easily understandable models, on the one hand, and that reflected by the existing observations, on the other (see, again, Ghil et al., 1991a; Ghil, 1995; and further references therein). A number of scalar quantities are obtained by applying the theory to univariate time series, such as the leading Lyapunov exponents or the various dimensions associated with the dynamical system that presumably produced the time series in question (Guckenheimer and Holmes, 1983; Drazin and King, 1992). The leading Lyapunov exponent provides a nonlinear generalization of the linear stability of a steady state; its being positive indicates that the system it characterizes is chaotic. Of the various phase-space dimensions (Eckmann and Ruelle, 1985) used to quantify a dynamical system's number of independent degrees of freedom, the correlation dimension (Grassberger and Procaccia, 1983) became best known for its ease of computation. 
In the study of climate variability across the modeling hierarchy, it is useful to apply more sophisticated numerical tools of ergodic theory than those that produce the scalar quantities above. These tools for the investigation of spatio-temporal regularities include various methods of cluster analysis for the classification of multiple weather regimes (Cheng and Wallace, 1993; Kimoto and Ghil, 1993a, b) and advanced methods for the analysis and prediction of uni- and multivariate time series (Vautard and Ghil, 1989; Plaut and Vautard, 1994; Dettinger et al., 1995; Ghil and Jiang, 1998).

These ideas from dynamical systems theory will be illustrated in the remainder of this chapter by applying them, in succession, to low-frequency atmospheric variability (Sec. II), seasonal-to-interannual climate variability (Sec. III), and decade-to-century variability in the THC (Sec. IV). In each section, the basic phenomena to be explained will be presented, the main ingredients for the solution of the climate problem thus posed will be derived by the use of simple models, and the rungs of the hierarchy climbed up to GCMs. In Sec. II these will be atmospheric GCMs, in Sec. III coupled GCMs, and in Sec. IV ocean GCMs and hybrid models. A possible road map for the further integration of GCMs into systematic climate-problem solving will be discussed in Sec. V.

\section{Intraseasonal oscillations, their theory and simulation}

Intraseasonal time scales range from the deterministic limit of atmospheric predictability, of about 10 days, up to a season, say 100 days. They occupy a window of overlap between short climatic time scales and low-frequency variability intrinsic to the atmosphere. These time scales are of particular importance to extended-range weather prediction. There are two complementary ways of describing low-frequency atmospheric variability: i) episodic, via multiple weather (Reinhold and Pierrehumbert, 1982) or flow (Legras and Ghil, 1985) regimes, and (ii) oscillatory, via broad-peak, slowly modulated oscillations (Ghil et al., 1991a, and references therein). We restrict ourselves here to the latter. 


\section{A. Extratropical oscillations: observations and theory}

Variations in global atmospheric angular momentum (AAM) and in the length of day on intraseasonal time scales are highly correlated with each other; both quantities exhibit spectral peaks with periods near 40 and 50 days (Dickey et al., 1991), among others. Essentially, the Earthatmosphere system is closed with respect to angular momentum exchanges on this time scale, except for the well-known tidal effects of the Sun and Moon, that can be easily computed and eliminated. Once this is done, what remains is the following: when the midlatitude westerly winds pick up, or the tropical easterlies slow down, the solid earth slows down in its rotation, and the length of day increases; hence the high positive correlation between the latter and AAM.

The latitude-frequency dependence of observed AAM variance is shown in Fig. 1, averaged over twelve years and all seasons. It is clear from the figure that the 50-day peak is largely associated with AAM fluctuations in the tropics, which dominate the global AAM. The 40-day peak, however, appears to be associated primarily with variations in the strength of the midlatitude westerlies: such a peak appears both in the Northern Hemisphere (NH) and in the Southern Hemisphere. The amplitude of the 40-day oscillations in zonal winds is known, however, to be largest during boreal winter, when the winds are strongest in the NH (Weickmann et al., 1985; Ghil and Mo, 1991; Strong et al., 1993, 1995), and we shall thus concentrate here on the longer data sets and more detailed modeling studies for the $\mathrm{NH}$.

[Fig. 1 near here, please.]

The extent to which the tropical and $\mathrm{NH}$ oscillations are independent phenomena or influence each other is still the subject of active debate. The tropical oscillation was discovered by Madden and Julian $(1971,1972)$ in zonal winds and tropical convection over the equatorial Pacific, although its origins are still not well understood. Extratropical oscillations have been found in observed NH planetary-scale circulation anomalies with periods of 20-70 days (Branstator, 1987; Kushnir, 1987; Ghil and Mo, 1991; Plaut and Vautard, 1994). There is some evidence that the midlatitude circulation over the North Pacific is correlated to convective anomalies associated with 
the tropical oscillation (Weickmann et al., 1985; Lau and Phillips, 1986; Higgins and Mo, 1997). On the other hand, Dickey et al. (1991) and Ghil and Mo (1991) found the extratropical mode to be often independent of, and sometimes to lead the tropical one. Upper-level potential vorticity anomalies are known to propagate from the midlatitudes into the tropics, associated with northwestto-southeast tilting troughs (Liebmann and Hartmann, 1984). They are accompanied by cold surges and can cause episodes of intense tropical convection that appear to be related to the intraseasonal oscillation in the tropics (Lau and Li, 1984; Hsu et al., 1990).

Our focus here is on how a hierarchy of models can be used to formulate and test the hypothesis that the 40-day oscillation is an intrinsic mode of the NH extratropics, associated with the interaction of the jet stream with midlatitude mountain ranges. The rudiments of this hypothesis originate in the highly idealized "toy" barotropic model of Charney and DeVore (1979), which was used to study the interaction between a zonal flow and simple zonal-wavenumber 2 topography. Their model exhibits two stable equilibria for the same strength of the prescribed zonal forcing, which represents the strength of the pole-to-equator temperature contrast.

Figure 2a shows the model's bifurcation diagram, with the strength $\psi_{A}$ of the zonal jet in the model's steady-state solutions plotted against the corresponding strength $\psi_{A}^{*}$ of the forcing. The two stable equilibria—-marked Z and R_— are associated with "zonal" (higher AAM) and "blocked" (lower AAM) flow respectively, as illustrated in Fig. 2b. The near-zonal solution is close in amplitude and spatial pattern to the forcing jet and is influenced very little by the topography, while the blocked solution is strongly affected by it. In the blocked-flow solution, a ridge is located upstream of the "mountains," similar to the situation during a typical observed West Coast block. This configuration, with a negative zonal pressure gradient on the windward slope of the mountains, corresponds to a negative mountain torque on the atmosphere.

[Fig. 2 near here, please.]

More complex models—-both barotropic and baroclinic, with more spatial degrees of freedom than Charney and DeVore's (1979)_-have been found to exhibit multiple flow patterns that are similar to those just described, for realistic values of the forcing. The crucial difference in these 
models is that the equilibria are no longer stable, and the system oscillates around the blocked solution or fluctuates between the zonal and blocked solutions in an irregular way (Legras and Ghil, 1985).

Jin and Ghil (1990) showed that, when a sufficiently realistic meridional structure of the solutions' zonal jet is allowed, the back-to-back saddle-node bifurcations of Fig. 2a are replaced by Hopf bifurcation and thus transition to finite-amplitude periodic solutions-also called limit cycles (see Sec. I.C)—can occur. Eigenanalyses of the unstable equilibria in a higher-resolution barotropic model, as well as its time-dependent solutions, also indicate oscillatory instabilities with intraseasonal (35-50 days) and biweekly (10-15 days) time scales (Strong et al., 1993). Floquet analysis of this model's limit cycles (Strong et al., 1995) confirms that the 40-day oscillations that arise in it by oscillatory topographic instability are stronger in winter than in summer, like the $\mathrm{NH}$ observed oscillations (Knutson and Weickmann, 1987; Ghil and Mo, 1991).

\section{B. GCM simulations and their validation}

Atmospheric GCMs provide a powerful tool for testing the theory of NH extratropical oscillations developed in simpler models. Marcus et al. $(1994,1996)$ made a 3-yr perpetual-January simulation with a version of the UCLA GCM that produces no self-sustained Madden-Julian oscillation in the tropics. A robust 40-day oscillation in AAM is found to arise in the model's NH extratropics when standard topography is present. Three shorter runs with no topography produced no intraseasonal oscillation, consistent with a topographic origin for the $\mathrm{NH}$ extratropical oscillation in the standard model. The spatial structure of the circulation anomalies associated with the model's extratropical oscillation is shown in Fig. 3, in terms of 500-mb geopotential height composites during the peak (panel a) and quadrature (panel b) phase of the AAM cycle.

[Fig. 3 near here, please.]

The oscillation is dominated by a standing, wavenumber-two pattern, which undergoes tilted-trough vacillation. High values of AAM are associated with low 500-mb heights over the northeast Pacific and Atlantic Oceans (Fig. 3a), and vice-versa. This resembles the configuration 
seen in Charney and DeVore's (1979) simple model (see Fig. 2b here). The GCM's NE-SW tilting phase in Fig. 3a and NW-SE tilting phase in Fig. 3b are strongly reminiscent of the extremes and intermediate phases of the 40-day oscillation that arises by Hopf bifurcation from the blocked equilibrium in the Legras and Ghil (1985) model (M. Kimoto, pers. commun., 1986).

The successive phases of the 28-72-day band-passed fluctuations in 250-mb streamfunction anomalies analyzed by Weickmann et al. (1985; see Figs. 7 and 9a-d there) also exhibit good agreement with the evolution of the 40-day oscillation in the work of Marcus and colleagues with the UCLA atmospheric GCM (see Ghil et al., 1991b, for a video clip of the evolution of 500-mb heights, 250-mb streamfunction fields, and sea-level pressures during the atmospheric GCM's 40-day oscillation). The height pattern in Fig. 3a is very similar, furthermore, to the extreme-phase patterns obtained from observed data by correlating the 10-day low-pass filtered wintertime 500-mb height fields with the sum of the mountain torques computed over the Rockies, Himalayas and Greenland (F. Lott, A. W. Robertson and M. Ghil, 1999, in preparation).

In the GCM, the two centers of action have slightly different frequencies; this gives rise to a long-period modulation (of about 300 days) in the amplitude of the intraseasonal oscillation, similar to that observed by Penland et al. (1991) in globally averaged AAM time series. Global correlations with the leading empirical orthogonal functions (EOFs) of the NH extratropical 500-mb height field show NE-SW teleconnection patterns extending into the tropics, in particular into the Indian Ocean, similar to those found in observational studies (Weickmann et al., 1985; Murakami, 1988). The model's zonally averaged latent heating in the tropics exhibits no intraseasonal periodicity, but a near 40-day oscillation is found in cumulus precipitation over the western Indian Ocean, suggesting an extratropical trigger of the 50-day oscillation in the tropics. Madden and Speth (1995; see Fig. 10 there) find that (mostly extratropical) mountain torques do lead (mostly tropical) friction torques and eastward-moving convective systems during the 1987-88 winter singled out already by Dickey et al. (1991; their Fig. 16).

Thus the careful analysis of perpetual-January runs with an atmospheric GCM confirms, on the one hand, the topographic origin of the NH 40-day oscillation, originally suggested by simple- 
and intermediate-model studies (Ghil and Childress, 1987, Sec. 6.4; Jin and Ghil, 1990). On the other, it provides greater realism and spatio-temporal detail, thus permitting a much better confrontation of the theory with the existing observations (Dickey et al., 1991; Ghil and Mo, 1991).

\section{El Niño-Southern Oscillation, from the Devil's Staircase to prediction}

\section{A. ENSO's regularity and irregularity}

The El Niño-Southern Oscillation (ENSO) phenomenon dominates interannual climate variability over the tropical Pacific, and influences the atmosphere globally. Figure 4 shows the power spectrum of the monthly sea-surface temperatures (SSTs) averaged over the eastern equatorial Pacific's Niño-3 area $\left(150^{\circ} \mathrm{W}-90^{\circ} \mathrm{W}, 5^{\circ} \mathrm{S}-5^{\circ} \mathrm{N}\right)$, for the time interval 1960-97. The spectrum is plotted in terms of the leading EOFs of a singular-spectrum analysis (SSA: Vautard and Ghil, 1989; Vautard et al., 1992). Pairs of EOFs that are in phase quadrature with each other correspond to nonlinear, anharmonic counterparts of sine-and-cosine pairs in standard Fourier analysis (Dettinger et al., 1995; Jiang et al., 1995a).

[Fig. 4 near here, please.]

The observed SST time series contains a sharp annual cycle, together with two broader interannual peaks centered at periods of 44 and 28 months. This power spectrum provides a fine example of the distinction between the sharp lines produced by purely periodic forcing and the broader peaks resulting from internal climate variability or from the interaction of the latter with the former (see the beginning of Sec. I). The sharp annual peak reflects the seasonal cycle of heat influx into the tropical Pacific and the phase locking of warm events to boreal winter that gives El Niño its name. The two interannual peaks correspond to the low-frequency and quasi-biennial (QB) components of ENSO identified by a number of authors (Rasmusson et al., 1990; Allen and Robertson, 1996). Jiang et al. (1995a) have demonstrated that major warm (El Niño) and cold (La Niña) events during the time interval 1950-90 can be well reconstructed from ENSO's quasi- 
quadrennial and QB components (see Fig. 9 there). Together, these two components account for about $30 \%$ of the variance in the time series analyzed in Fig. 4.

In spite of the marked regularities apparent from Fig. 4 and its discussion, forecasting El Niño and La Niña events has met with mixed success, even for subannual lead times (Latif et al., 1994): year-to-year variations in forecast skill at 6-12-month lead time have been noticed by the authors of the over a dozen models that routinely produce ENSO forecasts on a quarterly basis (see Sec. III.C below). Any satisfactory theory of ENSO should produce consistently reliable forecasts at such lead times. To do so, the theory must account for the observed low-frequency and QB peaks and the close relationship of these two with the annual cycle, on the one hand, as well as for the irregular occurrence of extreme events, on the other.

Much of our theoretical understanding of ENSO comes from relatively simple, essentially 0- and 1-D coupled models, consisting of a shallow-water or two-layer ocean model coupled to steady shallow-water-like atmospheric models with heavily parameterized physics (see Sec. I.B and references there); the more complete ones among these models are often called intermediate coupled models (Neelin et al., 1994). In these models, ENSO-like variability has been shown to result from an oscillatory instability of the coupled ocean-atmosphere's annual-mean climatological state. Its nature has been investigated in terms of the dependence of the primary Hopf bifurcation on fundamental parameters, such as the coupling strength, oceanic adjustment time scale, and the strength of surface currents (Jin and Neelin, 1993).

The growth mechanism of ENSO is undisputed, arising from positive atmospheric feedbacks on equatorial SST anomalies via the surface wind stress, as first hypothesized by Bjerknes (1969). The cyclic nature of the unstable mode is more subtle and depends on the time scales of response within the ocean. Recently, there has been renewed interest in the thermal discharge-recharge hypothesis of Cane and Zebiak (1985) and Wyrtki (1986). Here the memory of the system resides in a disequilibrium between the wind stress and the meridional exchange of heat between equatorial and off-equatorial regions (Jin, 1997). 


\section{B. The Devil's Staircase across the modeling hierarchy}

Regarding the relationship between El Niño and the annual cycle, Chang et al. (1994), Jin et al. (1994) and Tziperman et al. (1994) found that including an annual cycle in the basic state of their simple or intermediate models changed only slightly the spatial structure of the oscillatory instability. However, it caused the ENSO cycle to frequency-lock to rational multiples of the annual frequency in a "Devil's Staircase." This "staircase" represents a scenario of transition to deterministic chaos, and involves two parameters: as one changes a parameter that increases the period of the intrinsic ENSO instability, frequency-locking to successively longer rational multiples of the annual cycle occurs, according to the mechanism of subharmonic resonance (see Fig. 5a). As a second parameter, the coupling strength between the model's ocean and atmosphere, increases, the steps on the staircase broaden and begin to overlap (compare Fig. 5b to Fig. 5a), and the model's ENSO cycle becomes irregular due to jumps between the steps.

[Fig. 5 near here, please.]

Moving one rung higher in the model hierarchy, hybrid coupled models, consisting of an ocean GCM coupled to a simple atmosphere, have been used for sensitivity studies in a more realistic setting. Syu et al. (1995) demonstrated that introducing an annual cycle caused the period of oscillation in their model to shift from 2.3 years to exactly 2 years, and thus to frequency lock with the annual cycle in the manner predicted by theory.

At the top of the model hierarchy, over a dozen coupled ocean-atmosphere GCMs have now been used to simulate the climate variability of the tropical Pacific (Neelin, Latif, et al., 1992; Mechoso, Robertson, et al., 1995). These coupled GCMs have exhibited a wide range of seasonal and interannual behavior, with different amplitudes and phases of the seasonal cycle (Mechoso, Robertson, et al., 1995), as well as different periods, amplitudes and spatio-temporal characteristics of the interannual variability (Neelin, Latif, et al., 1992), and with zonally propagating or standing SST anomalies. 
For example, Robertson et al. (1995a, b) investigated the seasonal cycle and interannual variability in 45 years of simulations with the UCLA atmospheric GCM, coupled to a tropicalPacific basin version of the Geophysical Fluid Dynamics Laboratory (GFDL) ocean GCM; the latter is a descendent of Bryan and Cox's (1967) model (see Sec. I.B above) and the entire coupled GCM is described in detail by Mechoso (1999) in the present volume. The simulations were found to be characterized by ENSO-like QB and quasi-quadrennial modes, identified by using multichannel SSA (Plaut and Vautard, 1994) along the equator, but with weaker variability than the observed. Two simulations that differed only in details of the atmospheric GCM's surface-layer parameterizations are of particular interest, because the first (Decade I) was found to be dominated by a QB oscillation (Fig. 6a), while a quasi-quadrennial period dominated the second (Decade II: Fig. 6b).

[Fig. 6 near here, please]

A 100-year-long simulation with NASA Goddard's Aries-Poseidon coupled GCM exhibits both quasi-quadrennial and QB spectral peaks (P. Schopf and M. Suarez, pers. commun., 1995) of a strength very similar to that observed in the Cooperative Ocean-Atmosphere Data Set (COADS) (Fig. 7a). These results are further confirmed by a 60-year run of NCEP's coupled GCM (Ji et al., 1998; see Fig. 7b).

[Fig. 7 near here, please.]

The complete Devil's Staircase scenario, in fact, calls for successively smaller peaks associated with the harmonics of the 4-year step, at 4/1=4, 4/2=2, and 4/3 years. Both the QB and 4/3-year = 16-month peak are present in observed SST data (Jiang et al., 1995a; Allen and Robertson, 1996). There is a smaller and broader 18-20 month peak present in the UCLA coupled GCM in Fig. 6b, which can be interpreted as a merged version of these two peaks.

Work with intermediate coupled models suggests that the results shown in Figs. 6 and 7, together with those obtained using other coupled GCMs, can be explained in terms of each GCM simulation's location in the space spanned by a set of fundamental parameters, analogous to those that appear in the simple model of Jin and Neelin (1993). Clearly, however, the value of a simplified 
model parameter, such as "coupling strength," has a nontrivial expression in terms of the various physical parameterizations in the coupled GCM.

Figure 8 illustrates the spatial structure of the quasi-quadrennial mode along the equator in the UCLA coupled model, derived from multichannel SSA of a 26-year extension of the second simulation (Fig. 6b). The model's QB mode (not shown) has a structure that resembles that of Fig. 8. This common structure consists of predominantly standing oscillations in SST and zonal wind stress that peak in the central or east Pacific, accompanied by an oscillation in equatorial thermocline depth that is characterized by a phase shift of about $90^{\circ}$ across the basin-much less than the $180^{\circ}$ that Sverdrup balance would imply_-with west leading east. These features are all characteristic of observed ENSO events (Neelin et al., 1994).

[Fig. 8 near here, please.]

Simple and intermediate models suggest the following hypotheses for producing multiple, broad spectral peaks in the interannual band: (1) the quasi-quadrennial mode might arise by period doubling from the QB mode (Münnich et al., 1991); (2) the observed peaks may result from the linear superposition of several marginally damped modes, excited by white-noise forcing (Penland and Sardeshmukh, 1995); (3) stochastic resonance can cause intermittent jumps between the forced seasonal cycle and the lower-period internal ENSO cycle, in the presence of a certain level of noise (Stone et al., 1998); (4) the interaction of the seasonal cycle and the fundamental ENSO mode can nonlinearly entrain this mode to a rational multiple of the annual frequency and produce additional peaks, according to a Devil's Staircase (Chang et al., 1994; Jin et al., 1994; Tziperman et al., 1994); and (5) the quasi-quadrennial and QB peaks could represent separate oscillations, generated by different mechanisms, each with an independent frequency. The latter hypothesis, while not supported by explicit model results, is quite plausible when considering the differences in detailed ENSO mechanisms between models and the parameter dependence of the basic oscillation period for each model (see Neelin et al., 1998, and references therein).

The results of GCM simulations, along with existing observational data, provide a means of distinguishing between these alternatives. The fact that the variance associated with the low- 
frequency mode is actually larger than that associated with the QB mode in the observations ( $c f$. Jiang et al., 1995a, and Fig. 4 here) and that the two modes have comparable variance in the GCM simulations where they are both present (Figs. 7a, b here ) essentially rules out period doubling (hypothesis 1) as an explanation of ENSO irregularity, since that scenario would imply a much smaller quasi-quadrennial mode. The similarity of the spatial structures of the quasi-quadrennial and QB modes, both in coupled GCMs (Robertson et al., 1995b) and observations (Moron et al., 1998), weighs against hypothesis (5) of different physics producing two independent frequencies. In the case of the UCLA coupled GCM, variations in subsurface thermocline depth were similar in all three interannual frequencies isolated, also supporting this point.

The closeness of the quasi-quadrennial and QB peaks, in observations and the GCMs cited, to integer multiples of the annual period, on the other hand, and the observed 15-16-month peak in observed data are all consistent with subharmonic frequency locking (hypothesis 4). The basic similarity between the spatial structures of the ENSO modes and the annual cycle in the UCLA GCM is further evidence of an intimate relationship between ENSO variability and the annual cycle.

The low-frequency component of observed equatorial Pacific SSTs changes in period around 1960, from being near a 5-year period before, to a near-4-year period after 1960 (Moron et $a l ., 1997)$. This fairly abrupt change in frequency can be interpreted in terms of frequency locking to different integer multiples of the annual period, and thus to different steps on the Devil's Staircase in Fig. 5b.

The stochastic resonance hypothesis is, in a sense, intermediate between the Devil's Staircase and the stochastically forced linear-model hypothesis (2). The latter is rendered less plausible by the fact that it does not produce phase locking of individual warm and cold events to the boreal winter; it is the preference of warm events to peak in or near late December that gives El Niño its name (see, for instance, the histograms of warm events vs. calendar month in Figs. 3 and 5 of Chang et al., 1996). On the other hand, Jin et al. (1996) found that when "weather noise" is included in their model of the Devil's Staircase, the resulting irregularity still carries the signature of the subharmonic spectral peaks. It is difficult to tell in which way, if any, the stochastic- 
resonance model of Stone et al. (1998) differs from the stochastically perturbed version of the Devil's Staircase considered by Jin et al. (1996) and whether a subtle difference, if it exists, can be validated by the existing observations or GCM simulations, one way or the other.

\section{Regularity and prediction}

The standard application of dynamical systems theory to forecast error growth and predictability involves low-order dynamical systems that are entirely chaotic, i.e., have a purely continuous power spectrum, such as the Lorenz (1963a) system. For such systems, the leading Lyapunov exponents (e.g., Eckmann and Ruelle, 1985) are positive, and the largest one, $\lambda_{1}$ say, gives a rough estimate of the predictability limit $T_{\mathrm{p}} ; T_{\mathrm{p}}$ can be defined as the time it takes for a typical observation error $e_{0}$ to grow until it reaches an asymptotic level determined by the total energy available to the system. The rough estimate $\hat{T}_{\mathrm{p}}$ is based on the error growing at the rate $\exp \left(\lambda_{1} t\right)$ until it saturates at a level given by the system's climatological variance, $\sigma_{\infty}$ say, according to

$$
e_{0} \exp \left(\lambda_{1} \hat{T}_{\mathrm{p}}\right)=\sigma_{\infty}
$$

The error-growth curve in forced-dissipative systems (e.g., Ghil and Childress, 1987, Sec. 5.4) actually deviates from being exponential and has an inflection point before saturation (e.g., Kalnay and Dalcher, 1987), so Eq. (3.1) above will tend to underestimate the system's true $T_{\mathrm{p}}$. This is compensated for by the fact that the full system's additional degrees of freedom, which are usually neglected in deriving the simplified system for which $\lambda_{1}$ and hence the estimate $\hat{T}_{\mathrm{p}}$ in Eq. (3.1) is obtained, contribute additional error growth, often approximated as stochastic forcing in the simplified system. This permits (3.1) for the simplified, deterministic system with a few degrees of freedom — say a simple or intermediate model, in the terminology of Secs. I.A and I.B — to give a reasonable approximation for the full system, with its infinity of degrees of freedom. 
There is, however, an additional source of predictability in systems that have periodic or nearly periodic components, expressed as pure lines or broad peaks in their power spectrum. The fact that the days are warmer than the nights or summers than winters is useful, predictable information, independently of the change in average 24-hour or one-year temperature over a week or a decade, as the case may be. Both examples are derived from purely periodic, externally forced phenomena. Similar considerations apply, however, to internal periodicities that might only be approximate, rather than exact and thus result in broad spectral peaks, rather than sharp lines (Ghil and Childress, 1987, Sec. 12.6). Examples of such regularities are the intraseasonal oscillations considered in Sec. II, the QB and low-frequency components of ENSO in this section, and the interdecadal oscillations of Sec. IV.

In the case of ENSO, a considerable battery of models have been used for experimental seasonal-to-interannual prediction of various indices, like the Southern Oscillation index (SOI: e.g., Keppenne and Ghil, 1992), or fields like the Niño-3 SST anomalies considered here. Over fifteen 6-12-month forecasts have been published every quarter in the Experimental Long-Lead Forecast Bulletin (ELLFB) of NOAA's Climate Prediction Center since 1992; since Fall 1997, the ELLFB has been published by the non-profit Center for Ocean-Land-Atmosphere Studies and is available electronically at http://grads.iges.org/ellfb. The ELLFB forecasts employ both dynamically and statistically based models. The statistical models span the range from classical time-domain methods for time-series prediction through neural-network methods, while the dynamical ones go from intermediate coupled models all the way to fully coupled GCMs.

Table I summarizes the forecast skill of six models that have been carrying out real-time ENSO predictions for a few years' time: Zebiak and Cane's (1987) is an intermediate coupled model, Barnett et al.'s (1993), a hybrid coupled model, Ji et al.'s (1994) a fully coupled GCM, while Barnston and Ropelewski's (1992), Van den Dool's (1994) and Jiang et al.'s (1995b) are all statistical. The skills at 6-month lead are quite comparable, with the correlation between the field being forecast and that actually observed equal to about $0.6-0.75$ for the decade 1984-93; this level 
of correlation skill easily outperforms persistence and is generally considered as useful (Barnston et al., 1994).

[Table I near here, please.]

The highest skill actually occurs in the table's last column, using a statistical model (Keppenne and Ghil, 1992; Plaut and Vautard, 1994) that is explicitly based on extracting and predicting the (nearly) periodic components of a time series. Ghil and Jiang (1998) argue that the explanation for the comparable forecast skill of dynamical and statistical models is that most of this skill—in the case of the coupled ocean-atmosphere system in the tropical Pacific-is due to the model's capturing, more or less correctly, the system's oscillatory modes, QB and low-frequency. Still, it is quite likely that the Ji et al.'s (1994) coupled GCM forecast of the rapid temperature rise in the eastern tropical Pacific that occurred during late summer and early fall 1997, a few months ahead of time, is due to its modeling correctly certain features of the nonlinear dynamics that are event-specific, rather than nearly periodic (see also Hollingsworth, 1999).

\section{Interdecadal oscillations in the oceans' thermohaline circulation}

\section{A. Theory and simple models}

Historically, the thermohaline circulation (THC) was first among the climate system's major processes to be studied using a very simple mathematical model and be shown to possess multiple equilibria (Stommel, 1961). A sketch of the Atlantic Ocean's THC and its interactions with the atmosphere and cryosphere on long time scales is shown in Fig. 9. These interactions can lead to climate oscillations with multi-millenial periods — such as the Heinrich events (Ghil, 1994, and references therein) — and are summarized in the figure's caption, following Ghil et al. (1987). An equally schematic view of the global THC is provided by the widely known "conveyor belt" diagram (e.g., Broecker, 1991), which does not commonly include these interactions. [Fig. 9 near here, please.]

Basically, the THC is due to denser water sinking, lighter water rising, and water-mass continuity closing the circuit through near-horizontal flow between the areas of rising and sinking. 
This is roughly the oceanic equivalent of the atmosphere's Hadley circulation, with two notable differences:

i) The ocean water's density $\rho$ is a function of temperature $T$ and salinity $S$, while that of the air depends on temperature and humidity.

ii) Water sinks in and near fairly concentrated regions of intense convection, currently located mostly in high latitudes, and rises diffusely over the rest of the ocean; air does rise most intensely in cumulus towers, but overall the areas of net rising and sinking air in a Hadley cell are quite comparable in extent, when viewed on the synoptic and planetary scales.

The effects of temperature and salinity on the ocean water's density, $\rho=\rho(T, S)$, oppose each other: the density $\rho$ decreases with increasing $T$ and increases with increasing $S$. It is these two effects that give the thermohaline circulation its name, from the Greek words for $T$ and $S$. In high latitudes, $\rho$ increases as the water loses heat to the air above and, if sea ice is formed, as the water underneath is enriched in brine. In low latitudes, $\rho$ increases due to evaporation but decreases due to heat flux into the ocean.

For the present climate, the temperature effect is commonly assumed to be stronger than the salinity effect, and ocean water is observed to sink in certain areas of the high-latitude North Atlantic and Southern Ocean - with very few and limited areas of deep-water formation elsewhere — and to rise everywhere else; thus thermohaline, $T$ more important than and hence before $S$. During some past geological times, deep water apparently formed near the equator; such an overturning circulation of opposite sign to that prevailing today has been dubbed halothermal, $S$ before $T$ (e.g., Kennett and Stott, 1991). The quantification of the relative effects of $T$ and $S$ on the oceanic water masses' buoyancy in high and low latitudes is far from complete, especially for paleocirculations; the association of the latter with salinity effects that exceed the thermal ones is thus rather tentative.

Stommel (1961) considered a two-box model, with two pipes connecting the two boxes, and showed that the system of two nonlinear, coupled ordinary differential equations (ODEs) which govern the temperature and salinity differences between the two well-mixed boxes has two stable 
steady-state solutions, distinguished by the direction of flow in the upper and lower pipe.

Stommel's paper was primarily concerned with distinct local convection regimes, and hence vertical stratifications, in the North Atlantic and Mediterranean (or Red Sea), say. Today, we mainly think of one box as representing the low latitudes and the other one the high latitudes in the global THC.

The next step in the hierarchical modeling of the THC is that of 2-D meridional-plane models (see Sec. I.B), in which the temperature and salinity fields are governed by coupled nonlinear partial differential equations (PDEs) with two independent space variables, latitude and depth, say. Given boundary conditions for such a model that are symmetric about the Equator, as are the PDEs themselves, one expects a symmetric solution, in which water either sinks near the poles and rises everywhere else (thermohaline) or sinks near the Equator and rises everywhere else (halothermal); these two symmetric solutions would correspond to the two equilibria of Stommel's (1961) box model.

In fact, Fig. 10 shows that symmetry breaking can occur, leading gradually from a symmetric two-cell circulation (Fig. 10a) to an antisymmetric one-cell circulation (approximately achieved in Fig. 10c). In between, all degrees of dominance of one cell over the other are possible, with one such intermediate state shown in Fig. 10b. A situation lying somewhere between Figs. $10 \mathrm{~b}$ and $10 \mathrm{c}$ seems to resemble most closely the meridional overturning diagram of the Atlantic Ocean in Fig. 9.

[Fig. 10 near here, please.]

This symmetry breaking can be described by a pitchfork bifurcation (e.g., Guckenheimer and Holmes, 1983):

$\dot{x}=\mu-x^{3}$.

Here $x$ stands for the amount of asymmetry in the solution, so that $x \quad 0$ is the symmetric branch, $\dot{x} \equiv d x / d t$ and $\mu$ is a parameter that measures the stress on the system. For $\mu<0$ the symmetric branch is stable, while for $\mu>0$ the two branches $x= \pm \sqrt{\mu}$ inherit its stability. 
Thus, Figs. 10b and 10c both lie on a solution branch of the 2-D THC problem for which the left cell dominates: say that North Atlantic Deep Water extends to the Southern Ocean's polar front, as it does in Fig. 9. According to Eq. (4.1), another branch exists, whose flow patterns are mirror images in the rectangular box's vertical symmetry axis (the "equatorial plane") of those in Figs. 10b and 10c. The existence of this second branch was verified numerically by Quon and Ghil (1992; their Fig. 16). Thual and McWilliams (1992) considered more complex bifurcation diagrams for a similar 2-D model and showed the equivalence of such a diagram for their 2-D model and a box-and-pipe model of sufficient complexity.

\section{B. Bifurcation diagrams for GCMs}

Bryan (1986) was the first to document transition from a two-cell to a one-cell circulation in a simplified GCM with idealized, symmetric forcing, in agreement with the three-box scenario of Rooth (1982). Internal variability of the THC was studied simultaneously in the late 1980s and early 1990s on various rungs of the modeling hierarchy, from Boolean delay equation models (socalled "formal conceptual models": Ghil et al., 1987; Darby and Mysak, 1993) through box models (Welander, 1986) and 2-D models (Quon and Ghil, 1995) to ocean GCMs. A summary of the different kinds of oscillatory variability found in the latter appears in Table II below. Additional GCM references for these three types of oscillations are given by McWilliams (1996). The interaction of the (multi-)millenial oscillations with variability in the surface features and processes shown in Fig. 9 is discussed by Ghil (1994).

[Table II near here, please]

One example of the interaction between atmospheric processes and the THC is given by Chen and Ghil (1996), who use a different kind of hybrid coupled model than that reviewed in Sec. III.B, to wit a (horizontally) 2-D EBM (see Sec. I.A) coupled to a rectangular-box version of the North Atlantic rendered by a low-resolution ocean GCM. This hybrid model's regime diagram is shown in Fig. 11a. A steady state is stable for high values of the coupling parameter $\lambda_{a o}$ or of the 
EBM's diffusion parameter $d$. Interdecadal oscillations with a period of 40-50 years are selfsustained and stable for low values of these parameters.

[Fig. 11 near here, please]

The self-sustained THC oscillations in question are characterized by a pair of vortices of opposite sign that grow and decay in quadrature with each other in the ocean's upper layers. Their centers follow each other anticlockwise through the northwestern quadrant of the model's rectangular domain. Both the period and the spatio-temporal characteristics of the oscillation are thus rather similar to those seen in a fully coupled GCM with realistic geometry (Delworth et al., 1993).

The transition from a stable equilibrium to a stable limit cycle, via Hopf bifurcation, in Chen and Ghil's hybrid coupled model is shown in Fig. 11b. The physical characteristics of the oscillatory instability that leads to the Hopf bifurcations have been described in further detail by Colin de Verdière and Huck (1999), using both a four-box ocean-atmosphere and a number of more detailed models.

\section{Perspectives}

Until about two decades ago, the tools of analytical and numerical bifurcation theory could be applied only to 0-D THC models (Stommel, 1961) or 0- and 1-D climate models (Held and Suarez, 1974; Ghil, 1976; North et al., 1981). We have illustrated in this review, by considering a few climate problems on different time scales, that the general theory can be combined with powerful numerical tools to study successive bifurcations across the hierarchy of climate models, all the way from 0-D global or box models (see above) to 2- and 3-D models: atmospheric (Legras and Ghil, 1985; Marcus et al., 1996), oceanic (Thual and McWilliams, 1992; Ghil and Quon, 1992, 1995) and coupled (Jin et al., 1994, 1996; Robertson et al., 1995b; Chen and Ghil, 1996).

Each bifurcation is associated with a specific linear instability of a relatively simple climate state - oscillatory in the case of Hopf bifurcations and purely exponential in the case of saddle- 
node or pitchfork bifurcations — whose nonlinear saturation leads to more complicated climate behavior. Following the bifurcation tree, from one rung of the modeling hierarchy to the next, permits us, therefore, to study with increasing detail and realism the basic physical mechanisms that lead to climate variability.

Typically, the first one or two bifurcations will be captured fairly well by a lower-order or otherwise very simple model of the climate problem of interest. As the model's number of degrees of freedom or otherwise its complexity increase, more complicated and realistic regimes of behavior will appear. These regimes can only be reached by additional bifurcations. The task of following bifurcations numerically off solution branches with greater and greater complexity becomes more and more challenging. Various continuation methods (Keller, 1978; Kubicek and Marek, 1983) have been applied to follow steady-state solution branches of more and more highly resolving atmospheric (Legras and Ghil, 1985), oceanic (Speich et al., 1995) and coupled (Dijkstra and Neelin, 1995) models. Projected increase of computer power should make it possible to apply such methods to currently available GCMs in the near future.

GCMs - atmospheric (Sec. II), oceanic (Sec. IV), and coupled (Secs. III and IV) provide climate-problem solutions that have the greatest spatio-temporal detail and, one hopes, the greatest degree of realism. It is these solutions, therefore, that provide the best opportunity for evaluating our theories of climate variability, developed by climbing the lower rungs of the modeling hierarchy, against the observational evidence, such as it exists.

Such an evaluation, given the irregular character of observed climate variability, needs to be informed by the ergodic theory of dynamical systems, which can describe this irregular behavior in a consistent way. The statistical tools of the latter theory, such as singular-spectrum analysis and other advanced spectral methods, have to be applied in parallel to the GCMs' simulations and to the relevant data sets. Studying the observed and simulated climate variability with the same sophisticated tools can help pinpoint the aspects of this variability that we have understood, and can therefore predict with confidence, and those that we have not. Fortunately, there are many more of the latter, and much work remains to be done. 
It is the authors' hope that the tools and points of view presented in this chapter will help to both diminish and increase the number of unsolved climate-variability problems.

Acknowledgments. M.G. would like to acknowledge the warm welcome he and his ideas received at UCLA from A.A., and many informative discussions since. A.W.R. would like to thank A.A. for sharing his deep physical insights on many occasions. Both authors enjoyed the AA-Fest Symposium very much and were encouraged by the quality of the other presentations to prepare their own for publication. Our co-authors and colleagues active in the three areas of climate dynamics reviewed (as shown by the list of references) are to be thanked for all we learned from them. We are especially grateful to Paul Schopf and Max Suarez for Fig. 7a, to Ming Ji for Fig. 7b, and to Alain Colin de Verdière for a preprint of his paper with Thierry Huck. Mike MacCraken, Steve Marcus, Jim McWilliams and an anonymous reviewer read the original manuscript carefully and made constructive comments that helped improve the final version. Our work in these areas is supported by an NSF Special Creativity Award and NASA grant NAG5-317 (M.G.) and by DOE grant DE-FG03-98ER62515 (A. W. R.). Françoise J. E. Fleuriau helped with the word processing and references. This is publication no. 5070 of UCLA's Institute of Geophysics and Planetary Physics.

\section{References}

- $\quad$ Adem, J. (1970). Incorporation of advection of heat by mean winds and by ocean currents in a thermodynamic model for long-range weather prediction. Mon. Weather Rev., 98, 776-786.

- $\quad$ Allen, M. R., and A. W. Robertson (1996). Distinguishing modulated oscillations from coloured noise in multivariate datasets. Clim. Dyn., 12, 775-784.

- $\quad$ Arakawa, A., and V. R. Lamb (1977). Computational design of the basic dynamical processes of the UCLA general circulation model. Methods Comput. Phys., 17, 173.265.

- $\quad$ Barnett, T. P., M. Latif, N. Graham, M. Flügel, S. Pazan, and W. White (1993). ENSO and ENSO-related predictability. Part I: Prediction of equatorial Pacific sea surface temperature with a hybrid coupled ocean-atmosphere model. J. Climate, 6, 1545-1566.

- $\quad$ Barnston, A.G., and C.F. Ropelewski (1992). Prediction of NESO episodes using canonical correlation analysis, J. Climate, 5, 1316-1345. 
- $\quad$ Barnston, A. G., H. M. van den Dool, S. E. Zebiak, T. P. Barnett, M. Ji, D. R. Rodenhuis , M. A. Cane, A. Leetmaa, N. E. Graham, C. R. Ropelewski, V. E. Kousky, E. A. O’Lenic, and R. E. Livezey (1994). Long-lead seasonal forecasts - Where do we stand? Bull. Amer. Met. Soc., 75, 2097-2114.

- $\quad$ Berloff, P. S., and S.P. Meacham (1997). The dynamics of an equivalent-barotropic model of the wind-driven circulation. J. Mar. Res., 55, 407-451.

- Bjerknes, J. (1969). Atmospheric teleconnections from the equatorial Pacific. Mon. Wea. Rev., 97, 163-172.

- $\quad$ Branstator, G. W. (1987). A striking example of the atmosphere's leading traveling pattern. J. Atmos. Sci., 44, 2310-2323.

- $\quad$ Broecker, W.S. (1991). The great ocean conveyor. Oceanography, 4, 79-89.

- $\quad$ Bryan, F.O. (1986). High-latitude salinity effects and interhemispheric thermohaline circulations. Nature, 323, 301-304.

- Bryan, K., and M. Cox (1967). A numerical investigation of the oceanic general circulation. Tellus, 19, 54-80.

- Budyko, M. I. (1969). The effect of solar radiation variations on the climate of the Earth. Tellus, 21, 611-619.

- $\quad$ Cane, M., and S. E. Zebiak (1985). A theory for El Niño and the Southern Oscillation. Science, 228, 1084-1087.

- $\quad$ Cess, R.D., G. L. Potter, J. P. Blanchet, G. J. Boer, S. J. Ghan, J. T. Kiehl, H. Le Treut, Z.-X. Li, X.-Z. Liang, J. F. B. Mitchell, J.-J. Morcrette, D.A. Randall, M. R. Riches, E. Roeckner, U. Schlese, A. Slingo, K. E. Taylor, W. M. Washington. R. T. Wetherald, and I. Yagai (1989). Interpretation of cloud-climate feedbacks as produced by 14 atmospheric general circulation models, Science, 245, 513-551.

- $\quad$ Cessi, P., and G. R. Ierley (1995). Symmetry-breaking multiple equilibria in quasi-geotropic, wind-driven flows. J. Phys. Oceanogr., 25, 1196-1205.

- $\quad$ Chang, P., B. Wang, T. Li, and L. Ji (1994). Interactions between the seasonal cycle and the Southern Oscillation - frequency entrainment and chaos in an intermediate coupled ocean-atmosphere model, Geophys. Res. Lett., 21, 2817-2820.

- $\quad$ Chang, P., L. Ji, H. Li, and M. Flügel (1996). Chaotic dynamics versus stochastic processes in El Niño-Southern Oscillation in coupled ocean-atmosphere models. Physica D, 98, 301-320.

- Charlock, T.P., and W. D. Sellers, (1980). Aerosol effects on climate: Calculations with timedependent and steady-state radiative-convective model. J. Atmos. Sci., 38, 1327-1341. 
- Charney, J. G., and J. G. DeVore (1979). Multiple flow equilibria in the atmosphere and blocking. J. Atmos. Sci., 36, 1205-1216.

- Chen, F., and M. Ghil (1995). Interdecadal variability of the thermohaline circulation and high-latitude surface fluxes. J. Phys. Oceanogr., 25, 2547-2568.

- $\quad$ Chen, F., and M. Ghil (1996). Interdecadal variability in a hybrid coupled ocean-atmosphere model. J. Phys. Oceanogr., 26, 1561-1578.

- $\quad$ Cheng, X., and J.M. Wallace (1993). Cluster analysis of the Northern Hemisphere wintertime 500-hPa height field: Spatial patterns. J. Atmos., 50, 2674-2696.

- Colin de Verdière, A., and T. Huck (1999). Baroclinic instability: An oceanic wavemaker for interdecadal variability. J. Phys. Ocean., sub judice.

- Constantin, P., C. Foias, B. Nicolaenko, and R. Témam (1989). Integral Manifolds and Inertial Manifolds for Dissipative Partial Differential Equations, Springer-Verlag, New York, $122 \mathrm{pp}$.

- Crafoord, C., and E. Källen (1978). A note on the condition for existence of more than one steady-state solution in Budyko-Sellers type models. J. Atmos. Sci., 35, 1123-1125.

- $\quad$ Darby M.S. , and L.A. Mysak (1993). A Boolean delay equation model of an interdecadal Arctic climate cycle. Clim. Dyn., 8, 241-246.

- Delworth, T.S., Manabe, and R.J. Stouffer (1993). Interdecadal variations of the thermohaline circulation in a coupled ocean-atmosphere model. J. Climate, 6,1993-2011.

- $\quad$ Dettinger, M. D., M. Ghil, C. M. Strong, W. Weibel, and P. Yiou (1995). Software expedites singular-spectrum analysis of noisy time series. Eos, Trans. AGU, 76, pp. 12, 14, 21.

- $\quad$ Dickey, J. O., M. Ghil, and S. L. Marcus (1991). Extratropical aspects of the 40-50 day oscillation in length-of-day and atmospheric angular momentum. J. Geophys. Res., 96, 22643-22658.

- Djikstra H. A., and J. D. Neelin (1995). On the attractors of an intermediate coupled equatorial ocean-atmosphere model. Dyn. Atmos. Oceans, 22, 19-48.

- $\quad$ Drazin, P.G., and G. P. King (Eds.) (1992). Interpretation of Time Series from Nonlinear Systems (Proc. IUTAM Symp. \& NATO Adv. Res. Workshop, University of Warwick, England; Physica D, 58). North-Holland, Amsterdam, 502 pp.

- $\quad$ Eckmann, J.-P., and D. Ruelle (1985). Ergodic theory of chaos and strange attractors. Rev. Mod. Phys., 57, 617-656 (addendum, Rev. Mod. Phys., 57, 1115, 1985). 
- $\quad$ Gallée, H., J.P. van Ypersele, Th. Fichefet, C. Tricot, and A. Berger (1991). Simulation of the last glacial cycle by a coupled, sectorially averaged climate - ice-sheet model. I. The climate model. J. Geophys. Res., 96, 13, 139-161.

- Ghil, M. (1976). Climate stability for a Sellers-type model. J. Atmos. Sci., 33, 3-20.

- $\quad$ Ghil, M. (1994). Cryothermodynamics: The chaotic dynamics of paleoclimate, Physica D, 77, $130-159$.

- $\quad$ Ghil, M. (1995). Atmospheric Modeling, in Natural Climate Variability on Decade-toCentury Time Scales, D.G. Martinson, K. Bryan, M. Ghil, M.D. Hall, T.R. Karl, E.S. Sarachik, S. Sorooshian, and L.D. Talley (Eds.), National Academy Press, Washington D.C., pp.164-168.

- $\quad$ Ghil, M., and S. Childress (1987). Topics in Geophysical Fluid Dynamics: Atmospheric Dynamics, Dynamo Theory and Climate Dynamics, Springer-Verlag, New York, 485 pp.

- $\quad$ Ghil, M., and K. C. Mo (1991). Intraseasonal oscillations in the global atmosphere. Part I: Northern Hemisphere and tropics. J. Atmos. Sci., 48, 752-779.

- $\quad$ Ghil, M., and R. Vautard (1991). Interdecadal oscillations and the warming trend in global temperatures time series, Nature, 350, 324-327.

- Ghil, M., and J. McWilliams (1994). Workshop tackles oceanic thermohaline circulation, Eos, Trans. AGU, 75, pp. 493, 498.

- $\quad$ Ghil, M., and N. Jiang (1998). Recent forecast skill for the El-Niño/Southern Oscillation. Geophysics. Res. Lett., 25, No. 2, 171-174.

- Ghil, M., A. Mullhaupt and P. Pestiaux (1987). Deep water formation and Quarternary glaciations, Clim. Dyn., 2, 1-10.

- Ghil, M., M. Kimoto, and J. D. Neelin (1991a). Nonlinear dynamics and predictability in the atmospheric sciences, Rev. Geophys., 29, Supplement (U.S. Nat'1 Rept. to Int'1 Union of Geodesy \& Geophys. 1987-1990), pp. 46-55.

- Ghil, M., S. L., Marcus, J. O. Dickey, and C. L. Keppenne (1991b). AAM the Movie. NTSC videocassette AVC-91-063, Caltech/NASA Jet Propulsion Laboratory, Pasadena, CA 91109 [available also from M. Ghil upon request].

- Grassberger, P., and I. Procaccia, 1983: Characterization of strange attractors. Phys. Rev. Lett., 50, 346-349.

- $\quad$ Guckenheimer, J., and P. Holmes (1983). Nonlinear Oscillations, Dynamical Systems and Bifurcations of Vector Fields, Springer-Verlag, New York, 453 pp. 
- Held, I.M., and M. J. Suarez (1974). Simple albedo feedback models of the icecaps. Tellus, 36, 613-628.

- $\quad$ Higgins, R. W., and K. C. Mo (1997). Persistant North Pacific anomalies and the tropical intraseasonal oscillation. J. Climate, 10, 223-244.

- Hollingsworth, A. (1999): Research and development for medium- and extended-range forecasts: Methods, results, and prospects, in this volume.

- Hsu, H. H., B. J., Hoskins, and F.-F. Jin (1990). The 1985-86 intra-seasonal oscillation and the role of topographic instabilities. J. Atmos. Sci., 47, 823-839.

- Ji, M., A. Kumar, and A. Leetmaa (1994). An experimental coupled forecast system at the National Meteorological Center: Some early results, Tellus, 46A, 398-418.

- Ji, M., Behringer, D. W., and A. Leetmaa (1998): An improved coupled model for ENSO prediction and implications for ocean initialization, Part II: The coupled model, 1022-1034.

- Jiang, N., J. D. Neelin, and M. Ghil (1995a). Quasi-quadrennial and quasi-biennial variability in the equatorial Pacific. Clim. Dyn., 12, 101-112.

- Jiang N., M. Ghil, and J. D. Neelin (1995b). Forecasts of equatorial Pacific SST anomalies by an autoregressive process using similar spectrum analysis, Experimental Long-Lead Forecast Bulletin (ELLFB), National Meteorological Center, NOAA, U.S. Department of Commerce, 4, No. 1, 24-27.

- Jiang, S., F.-F. Jin, and M. Ghil (1995c). Multiple equilibria, periodic, and aperiodic solutions in a wind-driven, doublee-gyre, shallow-water model, J. Phys. Oceanogr., 25, 764-786.

- Jin, F.-F. (1997). An equatorial ocean recharge paradigm for ENSO, Part I: Conceptual model. J. Atmos. Sci., 54, 811-829.

- Jin, F.-F., and M. Ghil (1990). Intraseasonal oscillations in the extratropics: Hopf bifurcation and topographic instabilities. J. Atmos. Sci., 47, 3007-3022.

- Jin, F.-F., and J. D. Neelin (1993). Modes of interannual tropical ocean-atmosphere interaction - a unified view. Part III: Analytical results in fully-coupled cases. J. Atmos. Sci., 50, 3523-3540.

- Jin, F.-F., J. D. Neelin, and M. Ghil (1994). El Niño on the Devil's Staircase: Annual subharmonic steps to chaos. Science, 264, 70-72.

- Jin, F.-F., J. D. Neelin, and M. Ghil (1996). El Niño/Southern Oscillation and the annual cycle: Subharmonic frequency-locking and aperiodicity. Physica D, 98, 442-465.

- $\quad$ Kalnay, E., and A. Dalcher (1987). Forecasting forecast skill. Mon. Wea. Rev., 115, 349-356. 
- $\quad$ Karaca, M., and D. Müller (1989). Simulation of sea surface temperatures with the surface heat fluxes from an atmospheric circulation model. Tellus, 41A, 32-47.

- $\quad$ Keller, H.B. (1978). Global homotopies and Newton methods. Nonlinear Analysis, C. de Boor and G. H. Golub (Eds.), Academic Press, pp. 73-94.

- $\quad$ Kennett, R. P., and L. D. Stott (1991). Abrupt deep-sea warming, paleoceanographic changes and benthic extinctions at the end of the Palaeocene. Nature, 353, 225-229.

- $\quad$ Keppenne, C.L., and M. Ghil (1992). Adaptive filtering and prediction of the Southern Oscillation index, J. Geophys. Res., 97, 20449-20454.

- $\quad$ Kimoto, M., and M. Ghil, 1993a: Multiple flow regimes in the Northern Hemisphere winter. Part I: Methodology and hemispheric regimes, J. Atmos. Sci., 50, 2625-2643.

- $\quad$ Kimoto, M., and M. Ghil, 1993b: Multiple flow regimes in the Northern Hemisphere winter. Part II: Sectorial regimes and preferred transitions, J. Atmos. Sci., 50, 2645-2673.

- $\quad$ Knutson, T. R., and K. M. Weickmann (1987). 30-60 day atmospheric oscillations: Composite life cycles of convection and circulation anomalies. Mon. Wea. Rev., 115, 1407-1436.

- $\quad$ Kraus, E., and J. Turner (1967). A one-dimensional model of the seasonal thermocline. Tellus, 19, 98-105.

- $\quad$ Kubicek, M., and M. Marek (1983). Computational Methods in Bifurcation Theory and Dissipative Structures. Springer-Verlag, 243 pp.

- $\quad$ Kushnir, Y. (1987). Retrograding wintertime low-frequency disturbances over the North Pacific Ocean. J. Atmos. Sci., 44, 2727-2742.

- $\quad$ Latif, M., T. P. Barnett, M. A. Cane, M. Flügel, N. E. Graham, H. von Storch, J.-S. Xu, and S. E. Zebiak (1994). A review of ENSO prediction studies. Climate Dyn., 9, 167-179.

- $\quad$ Lau, K.-M., and M.-T. Li (1984). The monsoon of East Asia and its global associations - A survey. Bull. Amer. Meteorol. Soc., 65, 114-125.

- $\quad$ Lau, K.-M., and T. J. Phillips (1986). Coherent fluctuations of extratropical geopotential height and tropical convection in intraseasonal time scales. J. Atmos. Sci., 43, 1164-1181.

- $\quad$ Legras, B., and M. Ghil (1985). Persistent anomalies, blocking and variations in atmospheric predictability. J. Atmos. Sci., 42, 433-471.

- $\quad$ Li, Z. X., and H. Le Treut (1992). Cloud-radiation feedbacks in a general circulation model and their dependence on cloud modelling assumptions. Clim. Dyn., 7, 133-139.

- $\quad$ Li, Z.-X., K. Ide, H. Le Treut, and M. Ghil, 1997: Atmospheric radiative equilibria in a simple column model. Clim. Dyn., 13, 429-440.

- $\quad$ Liebmann, B., and D. L. Hartmann (1984). An observational study of tropical-midlatitude interaction on intraseasonal time scales during winter. J. Atmos. Sci., 41, 3333-3350. 
- Lorenz, E. N. (1963a). Deterministic nonperiodic flow. J. Atmos. Sci., 20, 130-141.

- $\quad$ Lorenz, E. N. (1963b). The mechanics of vacillation. J. Atmos. Sci., 20, 448-464.

- $\quad$ Lorenz, E.N. (1964). The problem of deducing the climate from the governing equations. Tellus, 16, 1-11.

- $\quad$ MacCracken, M.C., and S.J. Ghan (1988). Design and use of zonally averaged models, in Physically-Based Modeling and Simulation of Climate and Climatic Change, M.E. Schlesinger (Ed.), Kluwer Acad. Publishers, Dordrecht, pp. 755-803.

- Madden, R. A., and P. R. Julian (1971). Detection of a 40-50 day oscillation in the zonal wind in the tropical Pacific. J. Atmos. Sci., 28, 702-708.

- $\quad$ Madden, R. A., and P. R. Julian (1972). Description of global-scale circulation cells in the tropics with a 40-50 day period. J. Atmos. Sci., 29, 1109-1123.

- Madden, R.A., and P. Speth (1995). Estimates of atmospheric angular momentum, friction, and mountain torques during 1987-1988. J. Atmos. Sci., 52, 3681-3694.

- $\quad$ Manabe, S., and R. F. Strickler (1964). Thermal equilibrium of the atmosphere with a convective adjustment. J. Atmos. Sci., 21, 361-385.

- $\quad$ Marcus, S. L., Ghil, M., and Dickey, J. O. (1994). The extratropical 40-day oscillation in the UCLA General Circulation Model, Part I: Atmospheric angular momentum, J. Atmos. Sci., 51, 1431-1466.

- $\quad$ Marcus, S. L., Ghil, M., and Dickey, J. O. (1996). The extratropical 40-day oscillation in the UCLA General Circulation Model, Part II: Spatial structure, J. Atmos. Sci., 53, 1993-2014.

- Marotzke, J. (1989). Instabilities and multiple steady states of the thermohaline circulation, in Ocean Circulation Models: Combining Data and Dynamics, D. L. T. Anderson and J. Willebrand (Eds.), Kluwer Academic, pp. 501-511.

- McWilliams, J.C. (1996). Modeling the oceanic general circulation, Annu. Rev. Fluid. Mech. 28, 215-48.

- Mechoso, C. R. (1999). A coupled GCM pilgrimage: From climate catastrophe to ENSO simulations, in this volume.

- $\quad$ Mechoso, C. R., A. W. Robertson, N. Barth, M. K. Davey, P. Delecluse, P. R. Gent, S. Ineson, B. Kirtman, M. Latif, H. Le Treut, T. Nagai, J. D. Neelin, S. G. H. Philander, J. Polcher, P. S. Schopf, T. Stockdale, M. J. Suarez, L. Terray, O. Thual, and J. J. Tribbia (1995). The seasonal cycle over the tropical Pacific in coupled ocean-atmosphere general circulation models. Mon. Wea. Rev., 123, 2825-2838.

- $\quad$ Mikolajewicz, U., and E. Maier-Reimer (1990). Internal secular variability in an ocean general circulation model. Clim. Dyn., 4, 145-156.

$$
-36-
$$


- $\quad$ Mitchell, J. M., Jr. (1976). An overview of climatic variability and its causal mechanisms. Quartern. Res., 6, 481-493.

- $\quad$ Moron V., Vautard, R., and M. Ghil (1998). Trends, interdecadal and interannual oscillations in global sea-surface temperatures, Clim. Dyn., 14, 545-569.

- Münnich, M., M. A. Cane and S. E. Zebiak (1991). A study of self-excited oscillations in a tropical ocean-atmosphere system. Part II: Nonlinear cases. J. Atmos. Sci., 48, 1238-1248.

- Murakami, T. (1988). Intraseasonal atmospheric teleconnection patterns during the Northern Hemisphere winter. J. Climate, 1, 117-131.

- Neelin, J. D. (1990a). A hybrid coupled general circulation model for El Niño studies. J. Atmos. Sci., 47, 674-693.

- $\quad$ Neelin, J. D. (1990b). The slow sea surface temperature mode and the fast-wave limit: Analytic theory for tropical interannual oscillations and experiments in a hybrid coupled model. J. Atmos. Sci., 48, 584-606.

- $\quad$ Neelin, J. D., M. Latif, M. A. F. Allaart, M. A. Cane, U. Cubasch, W. L. Gates, P. R. Gent, M. Ghil, C. Gordon, N. C. Lau, C. R. Mechoso, G. A. Meehl, J. M. Oberhuber, S. G. H. Philander, P. S. Schopf, K. R. Sperber, A. Sterl, T. Tokioka, J. Tribbia, and S. E. Zebiak (1992). Tropical air-sea interaction in general circulation models. Climate Dyn., 7, 73-104.

- $\quad$ Neelin, J. D., M. Latif, and F.-F. Jin (1994). Dynamics of coupled ocean-atmosphere models: The tropical problem. Annu. Rev. Fluid Mech., 26, 617-659.

- $\quad$ Neelin, J. D., D. S. Battisti, A.C. Hirst, F.-F. Jin, Y. Wakata, T. Yamagata, and S.E. Zebiak (1998). ENSO theory, J. Geophys. Res., 103, 14261-14290.

- $\quad$ North, G. R., R. F. Cahalan, and J. A. Coakley, Jr. (1981). Energy balance climate models. Rev. Geophys. Space Phys., 19, 91-121.

- $\quad$ North, G. R., Mengel, J. G., and D. A. Short (1983). Simple energy balance model resolving the seasons and the continents: Application to the astronomical theory of the ice ages. $J$. Geophys. Res., 88, 6576-6586.

- $\quad$ Paillard, D., M. Ghil, and H. Le Treut (1993). Dissolved organic matter and the glacialinterglacial $\mathrm{pCO}_{2}$ problem. Global Biogeochem. Cycles, 7, 901-914.

- $\quad$ Penland, C., M. Ghil, and K. M. Weickmann (1991). Adaptive filtering and maximum entropy spectra, with application to changes in atmospheric angular momentum. J. Geophys. Res., 96, 22659-22671.

- $\quad$ Penland, C., and P. D. Sardeshmukh (1995). The optimal growth of tropical sea surface temperature anomalies. J. Climate, 8, 1999-2024.

- $\quad$ Pfeffer, R.L. (ed.) (1960). Dynamics of Climate. Pergamon Press, New York, 137 pp. 
- Plaut, G. R., and R. Vautard (1994). Spells of oscillations and weather regimes in the lowfrequency dynamics of the Northern Hemisphere. J. Atmos. Sci., 51, 210-236.

- $\quad$ Quon, C., and M. Ghil (1995). Multiple equilibria and stable oscillations in thermosolutal convection at small aspect ratio. J. Fluid. Mech., 291, 33-56.

- $\quad$ Ramanathan, V., and J.A. Coakley, J.A. (1978). Climate modeling through radioactive convective models. Rev. Geophys. Space Phys., 16, 465-489.

- $\quad$ Rasmusson, E. M., X. Wang, and C. F. Ropelewski (1990). The biennial component of ENSO variability. J. Marine Syst., 1, 71-96.

- $\quad$ Reinhold, B. B., and R.T. Pierrehumbert (1982). Dynamics of weather regimes: Quasistationary waves and blocking. Mon. Wea. Rev., 110, 1105-1145.

- Rennó, N. O., (1997). Multiple equilibria in radiative-convective atmospheres, Tellus, 49A, 423-438.

- $\quad$ Robertson, A. W., C.-C. Ma, C. R. Mechoso, and M. Ghil (1995a). Simulation of the Tropical-Pacific climate with a coupled ocean-atmosphere general circulation model. Part I: The seasonal cycle. J. Climate, 8, 1178-1198.

- $\quad$ Robertson, A. W., C.-C. Ma, M. Ghil, and R.C. Mechoso (1995b). Simulation of the Tropical-Pacific climate with a coupled ocean-atmosphere general circulation model. Part II: Interannual variability. J. Climate, 8, 1199-1216.

- $\quad$ Rooth, C. (1982). Hydrology and ocean circulation. Progr. Oceanogr., 11, 131-149.

- Salzman, B., and A. D. Vernekar (1972). Global equilibrium solutions for the zonally averaged macroclimate, J. Geophys. Res., 77, 3936-3945.

- $\quad$ Sarmiento, J.L., and J. R. Toggweiler (1984). A new model for the role of the oceans in determining atmospheric $\mathrm{pCO}_{2}$, Nature, 308, 621-624.

- $\quad$ Schlesinger M.E. (1986). Equilibrium and transient climatic warming induced by increased atmospheric CO2. Clim. Dyn., 1, 35-51.

- $\quad$ Schlesinger, M.E., and J.B. Mitchell (1987). Climate model simulations of the equilibrium climatic response to increased carbon dioxdide. Rev. Geophys., 25, 760-798.

- $\quad$ Schneider, S.H., and R.E. Dickinson (1974). Climate modeling. Rev. Geophys. Space Phys., 25, 447-493.

- $\quad$ Sellers, W. D. (1969). A climate model based on the energy balance of the earth-atmosphere system. J. Appl. Meteor., 8, 392-400.

- $\quad$ Smale, S. (1967). Differentiable dynamical systems. Bull. Amer. Math. Soc., 73, 747-817.

- $\quad$ Speich, S., H. Dijkstra, and M. Ghil (1995). Successive bifurcations in a shallow-water model, applied to the wind-driven ocean circulation, Nonlin. Proc. Geophys., 2, 241-268. 
- Stommel, H. (1961). Thermohaline convection with two stable regimes of flow. Tellus, 13, 224-230.

- $\quad$ Stone, L., P.I. Saparin, A. Huppert, and C. Price (1998). El Niño chaos: The role of noise and stochastic resonance on the ENSO cycle. Geophys. Res. Lett., 25, No. 2, pp. 175-178.

- $\quad$ Strong, C. M., F.-F. Jin, and M. Ghil (1993). Intraseasonal variability in a barotropic model with seasonal forcing. J. Atmos. Sci., 50, 2965-2986.

- $\quad$ Strong, C. M., F.-F. Jin, and M. Ghil (1995). Intraseasonal oscillations in a barotropic model with annual cycle, and their predictability. J. Atmos. Sci., 52, 2627-2642.

- Suarez, M. J., and P. S. Schopf (1988). A delayed action oscillator for ENSO. J. Atmos. Sci., 45, 3283-3287.

- $\quad$ Syu, H., J. D. Neelin, and D. Gutzler (1995). Seasonal and interannual variability in a hybrid coupled GCM. J. Climate, 8, 2121-2143.

- Thual, O., and J. C. McWilliams (1992). The catastrophe structure of thermohaline convection in a two-dimensional fluid model and a comparison with low-order box models. Geophys. Astrophys. Fluid Dyn., 64, 67-95.

- $\quad$ Tziperman, E., L. Stone, M. Cane, and H. Jarosh (1994). El Niño chaos: Overlapping of resonances between the seasonal cycle and the Pacific ocean-atmosphere oscillator. Science, 264, 72-74.

- Van den Dool, H. M. (1994). Searching for analogues, how long must we wait? Tellus, 46A, 314-324.

- $\quad$ Vautard, R., and M. Ghil (1989). Singular spectrum analysis in nonlinear dynamics, with applications to paleoclimatic time series. Physica D, 35, 395-424.

- Vautard, R., P. Yiou, and M. Ghil (1992). Singular-spectrum analysis: A toolkit for short, noisy chaotic signals, Physica D, 58, 95-126.

- $\quad$ Wang, X., P.H. Stone, and J. Marotzke (1999). Global thermohaline circulation, Part II: Sensitivity with interactive atmospheric transports, J. Climate, 12, 83-91.

- $\quad$ Weaver, A. J., E. S. Sarachik, and J. Marotzke (1991). Freshwater flux forcing of decadal and interdecadal oceanic variability. Nature, 353, 836-838.

- $\quad$ Weaver, A.J., J. Marotzke, P.F. Cummings, and E.S. Sarachick (1993). Stability and variability of the thermohaline circulation. J. Phys. Oceanogr., 23, 39-60.

- Weickmann, K. M., G. R. Lussky, and J. E. Kutzbach (1985). Intraseasonal (30-60 day) fluctuations of outgoing longwave radiation and $250 \mathrm{mb}$ streamfunction during northern winter. Mon. Wea. Rev., 113, 941-961. 
- Welander, P. Thermohaline effects in the ocean circulation and related simple models, in Large-Scale Transport Processes in Oceans and Atmosphere, Willebrand and D. L. T. Anderson (Eds.), D. Reidel, pp. 163-200.

- Weng, W., and J. D. Neelin (1998). On the role of ocean-atmosphere interaction in midlatitude interdecadal variability, Geophys. Res. Lett., 25, No. 2, 167-170.

- Wetherald, R.T., and S. Manabe (1975). The effect of changing the solar constant on the climate of a general circulation model, J. Atmos. Sci., 32, 2044-2059.

- Wyrtki, K. (1986). Water displacements in the Pacific and the genesis of El Niño cycles. $J$. Geophys. Res., 91, 7129-7132. 
- Table I. The characteristics and 6-month-lead skill of six ENSO forecast models, three of them dynamical and three statistical. Reproduced from Ghil and Jiang (1998), with the permission of the American Geophysical Union.

\begin{tabular}{|c|c|c|c|c|c|c|}
\hline Authors & $\begin{array}{l}\text { Zebiak } \\
\text { \& Cane } \\
(1987)^{*}\end{array}$ & $\begin{array}{l}\text { Barnett et al. } \\
(1993)^{*}\end{array}$ & $\begin{array}{l}\text { Ji et al. } \\
(1994) *\end{array}$ & $\begin{array}{l}\text { Barnston \& } \\
\text { Ropelewski* }\end{array}$ & $\begin{array}{l}\text { Van den } \\
\text { Dool } \\
(1994)^{*}\end{array}$ & $\begin{array}{l}\text { Jiang et al. } \\
(1995 \mathrm{~b})\end{array}$ \\
\hline Model & $\begin{array}{l}\text { Physical: } \\
\text { simple } \\
\text { coupled }\end{array}$ & $\begin{array}{l}\text { Hybrid: see } \\
\text { text }\end{array}$ & $\begin{array}{l}\text { Physical: } \\
\text { coupled } \\
\text { GCMs }\end{array}$ & $\begin{array}{l}\text { Statistical: } \\
\text { CCA }\end{array}$ & $\begin{array}{l}\text { Empirical: } \\
\text { constructed } \\
\text { analog }\end{array}$ & $\begin{array}{l}\text { Statistical: } \\
\text { SSA and M- } \\
\text { SSA }\end{array}$ \\
\hline $\begin{array}{l}\text { Predicted } \\
\text { SST region } \\
\left(5^{\circ} \mathrm{N}-5^{\circ} \mathrm{S}\right)\end{array}$ & $\begin{array}{l}\text { Niño-3 } \\
90^{\circ}-150^{\circ} \mathrm{W}\end{array}$ & $\begin{array}{l}\text { Central } \\
\text { Pacific } \\
140^{\circ}-180^{\circ} \mathrm{W}\end{array}$ & $\begin{array}{l}\text { Niño-3.4 } \\
120^{\circ}-170^{\circ} \mathrm{W}\end{array}$ & $\begin{array}{l}\text { Niño-3.4 } \\
120^{\circ}-70^{\circ} \mathrm{W}\end{array}$ & $\begin{array}{l}\text { Niño-3.4 } \\
120^{\circ}-170^{\circ} \mathrm{W}\end{array}$ & $\begin{array}{l}\text { Niño-3 } \\
90^{\circ}-150^{\circ} \mathrm{W}\end{array}$ \\
\hline $\begin{array}{l}\text { Period of } \\
\text { record }\end{array}$ & 1970-93 & 1966-93 & 1984-93 & 1956-93 & 1956-93 & 1984-93 \\
\hline (1982-93) & $\begin{array}{ll}\text { Corr } & 0.62 \\
\text { RMSE } & 0.95 \\
\text { SD } & 1.08\end{array}$ & $\begin{array}{ll}\text { Corr } & 0.65^{\mathrm{a}} \\
\text { RMSE } & 0.97 \\
\text { SD } & 1.10\end{array}$ & $\begin{array}{l}\text { Corr } 0.69^{b} \\
\text { RMSE } 0.83^{b} \\
\text { SD }\end{array}$ & $\begin{array}{ll}\text { Corr } & 0.66 \\
\text { RMSE } & 0.89 \\
\text { SD } & 1.11\end{array}$ & $\begin{array}{ll}\text { Cor } & 0.66 \\
\text { RMSE } & 0.89 \\
\text { SD } & 1.11\end{array}$ & $\begin{array}{ll}\text { Corr } & 0.74^{\mathrm{c}} \\
\text { RMSE } & 0.50^{\mathrm{c}} \\
\text { SD } & 1.00\end{array}$ \\
\hline
\end{tabular}

* After Table 1 of Barnston et al. (1994).

** Two measures of skill are provided: i) correlation (Corr) between prediction and validation anomaly fields (actual monthly values minus climatology) and ii) root-mean-square error (RMSE) of prediction vs. validation, normalized by the variability of the validating field. SD indicates the standard deviation of the observed SSTs over the time interval for which forecast results from each model were available.

a,b See Barnston et al. (1994) for details.

c The results in this column represent retroactive real-time forecasts, like those for the Barnston and Ropelewski (1992) and Van den Dool (1994) models; the only column in the table based exclusively on actual real-time forecasts is that for the Zebiak and Cane (1987) model. The "mixed" forecast skill (i.e., based in part on retroactive real-time and in part on actual real-time forecasts) of the Jiang et al. (1995b) model for the time interval January1984—December 1996 is Corr $=0.66$ and RMSE=0.53, with actual forecasts published in ELLFB since March 1995. The 1997-98 warm event was predicted by this model since December 1996. 
Table II. Thermohaline circulation (THC) oscillations. Adapted from Ghil (1994), with the permission of Elsevier Science B.V.

\begin{tabular}{l|l|l}
\hline \hline Time scale & Phenomena & Mechanism \\
\hline Interdecadal & $\begin{array}{l}\text { 3-D, wind-driven }+ \\
\text { thermohaline circulation }\end{array}$ & $\begin{array}{l}\text { - Gyre advection (Weaver } \text { et } \\
\text { al., 1991, 1993). } \\
\text { - Localized surface-density } \\
\text { anomalies due to surface } \\
\text { coupling (Chen and Ghil, } \\
\text { 1995, 1996). }\end{array}$ \\
\hline Centennial & $\begin{array}{l}\text { Loop-type, Atlantic-Pacific } \\
\text { circulation }\end{array}$ & $\begin{array}{l}\text { Conveyor-belt advection of } \\
\text { high-latitude density anomalies } \\
\text { (Mikolajewicz and Maier- } \\
\text { Reimer, 1990). }\end{array}$ \\
\hline Millennial & $\begin{array}{l}\text { Relaxation oscillation, with } \\
\text { "flushes" and superimposed } \\
\text { decadal fluctuations }\end{array}$ & $\begin{array}{l}\text { Bottom-water warming, due to } \\
\text { high-latitude freshening and } \\
\text { its braking effect (Marotzke, } \\
\text { 1989; Chen and Ghil, 1995). }\end{array}$ \\
\hline
\end{tabular}




\section{Figure Captions}

Figure 1: Latitude-frequency dependence of observed AAM variance, as shown by a contour plot of power spectral density for the 46 equal-area belts numbered from south to north. The power in each belt has been multiplied by the frequency; units are angular momentum squared $[(1 / 600) \mathrm{ms}]^{2}$. The contour interval is 5.0, with contours starting at 20.0; values over 40.0 are shaded. Reproduced from Dickey et al. (1991), with the permission of the American Geophysical Union.

Figure 2: Multiple equilibria of a three-mode quasi-geostrophic model with simplified forcing and topography. (a) Bifurcation diagram showing model response to changes in forcing; see text for the explanation of abscissa and ordinate. The S-shaped bifurcation curve is typical of two back-to-back saddle-node bifurcations that give rise to two stable solution branches (solid) separated by an unstable one (dashed). (b) Flow patterns of the zonal (upper panel) and blocked (lower panel) equilibria, corresponding to the two stable equilibria $\mathrm{Z}$ and $\mathrm{R}$. After Charney and DeVore (1979). Reproduced from Ghil and Childress (1987), with the permission of Springer Verlag.

Figure 3: Composite 500-mb maps from the perpetual-January GCM experiment of Marcus et al. (1996). (a) For days on which the 36-60 day NH extratropical AAM exceeded 1.5 times its rms value; maps for days with a negative (positive) anomaly were added with a positive (negative) sign. (b) Constructed from maps taken 12 days earlier than those included in (a). Contour interval is $20 \mathrm{~m}$, and negative contours are dashed. Reproduced from Marcus et al. (1996), with the permission of the American Meteorological Society.

Figure 4: Power spectrum of the leading reconstructed components (RCs) of the Niño-3 SSTs for the time interval 1960-97, using monthly data from the Climate Prediction Center of the National Centers for Environmental Prediction (NCEP). An SSA analysis with a window width of 72 months was used to derive the RCs, whose power spectra were then computed using the maximum entropy method, with 20 poles. The three curves show the annual cycle 
(short dashes), and the low-frequency (solid) and QB (long dashes) components of ENSO; notice logarithmic units on the ordinate.

Figure 5: The Devil's Staircase in the intermediate coupled ocean-atmosphere model of Jin et al. (1994), plotted in terms of the frequency ratio of the model's inherent ENSO period to the annual cycle, as a function of the parameter $\delta_{\mathrm{s}}$ that affects the former. The coupling parameter $\mu$ is the Hopf bifurcation parameter in the annual-average model of Jin and Neelin (1993). (a) The approximate Devil's Staircase for $\mu=\mu_{0}$, slightly above the primary Hopf bifurcation where the ENSO mode goes unstable; all points shown correspond to rational frequency ratios (some labeled). (b) Frequency-locked solutions for somewhat larger values of $\mu \approx 1.1 \mu_{\mathrm{O}}$, showing the rapid widening of the integer-period steps. Reproduced from Jin et al. (1996), with the permission of Elsevier Science B.V.

Figure 6: Equatorial SST anomaly indices from the UCLA coupled GCM, constructed from RCs of SST for (a) Decade I $\left(130^{\circ}-110^{\circ} \mathrm{W}, 4^{\circ} \mathrm{S}-4^{\circ} \mathrm{N}\right)$ and (b) Decade II $\left(160^{\circ}-140^{\circ} \mathrm{W}, 4^{\circ} \mathrm{S}-4^{\circ} \mathrm{N}\right)$. Key: solid line-RCs 1-2; dashed line-RCs 3-4; and dotted line-RCs 5-6. Reproduced from Robertson et al. (1995b), with the permission of the American Meteorological Society.

Figure 7a: Power spectrum of Niño-3 SST anomalies from 38 years of COADS data (1950-87) — dashed-dotted line—and from a 38-year segment out of a 100-year integration with the NASA Goddard Space Flight Center's coupled GCM—solid line. Shown are the first (quasi-quadrennial) and second (QB) pair of RCs from an SSA analysis with 100 monthly lags; the good match in amplitude between the two time series, for both spectral peaks, is significant, since neither data set was normalized (P. Schopf and M. Suarez, pers. commun., 1995). (b) Same as the solid line in panel (a) but based on a 60-year integration of NCEP's coupled GCM (Ji et al., 1998); SST anomalies courtesy of M. Ji (pers. commun., 1998) and spectral analysis as in Fig. 4. The monthly data in both panels were deseasonalized by subtracting the mean annual cycle, with a 3-month running average 
applied in (b); notice linear ordinate in both panels.

Figure 8: Hovmöller diagram along the equator, showing the structure of the quasi-quadrennial mode in the UCLA coupled GCM. Plotted are RCs 1-2 for the 26-year extension to

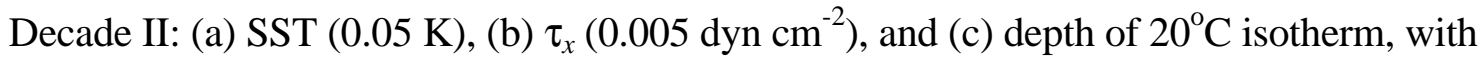
greater depth shown as negative $(1 \mathrm{~m})$; negative anomalies are stippled. Reproduced from Robertson et al. (1995b), with the permission of the American Meteorological Society. Figure 9: Diagram of an Atlantic meridional cross section from North Pole (NP) to South Pole (SP), showing mechanisms likely to affect the THC on various time-scales. Changes in the radiation balance $R_{\text {in }}-R_{\text {out }}$ are due, at least in part, to changes in extent of Northern Hemisphere $(\mathrm{NH})$ snow and ice cover, $V$, and how they affect the global temperature, $T$; the extent of Southern Hemisphere ice is assumed constant, to a first approximation. The change in hydrologic cycle expressed in the terms $P_{\text {rain }}-P_{\text {evap }}$ for the ocean and $P_{\text {snow }}-P_{\text {abl }}$ for the snow and ice is due to changes in ocean temperature. Deep-water formation in the North Atlantic Subpolar Sea (North Atlantic Deep Water: NADW) is affected by changes in ice volume and extent, and regulates the intensity $C$ of the THC; changes in Antarctic Bottom Water $(\mathrm{AABW})$ formation are neglected in this approximation. This in turn affects the system's temperature, and is also affected by it. Reproduced from Ghil and McWilliams (1994), after Ghil et al. (1987).

Figure 10: Stream-function fields for a 2-D, meridional plane THC model with so-called mixed boundary conditions: the temperature profile and salinity flux are imposed at one horizontal boundary of the rectangular box, while the other three boundaries are impermeable to heat and salt. (a) Symmetric solution for low salt-flux forcing; (b, c) increasingly asymmetric solutions as the forcing is increased. Reproduced from Quon and Ghil (1992), with the permission of Cambridge University Press.

Figure 11: Dependence of THC solutions on two parameters in a hybrid coupled model (HCM); the two parameters are the atmosphere-ocean coupling coefficient $\lambda_{a o}$ and the atmospheric 
thermal diffusion coefficient $d$. (a) Schematic regime diagram. The full circles stand for the model's stable steady states, the open circles for stable limit cycles, and the solid curve is the estimated neutral stability curve between the former and the latter. (b) Hopf bifurcation curve at fixed $d=1.0$ and varying $\lambda_{a o}$; this curve was obtained by fitting a parabola to the model's numerical-simulation results, shown as full and open circles. Reproduced from Chen and Ghil (1996), with the permission of the American Meteorological Society. 


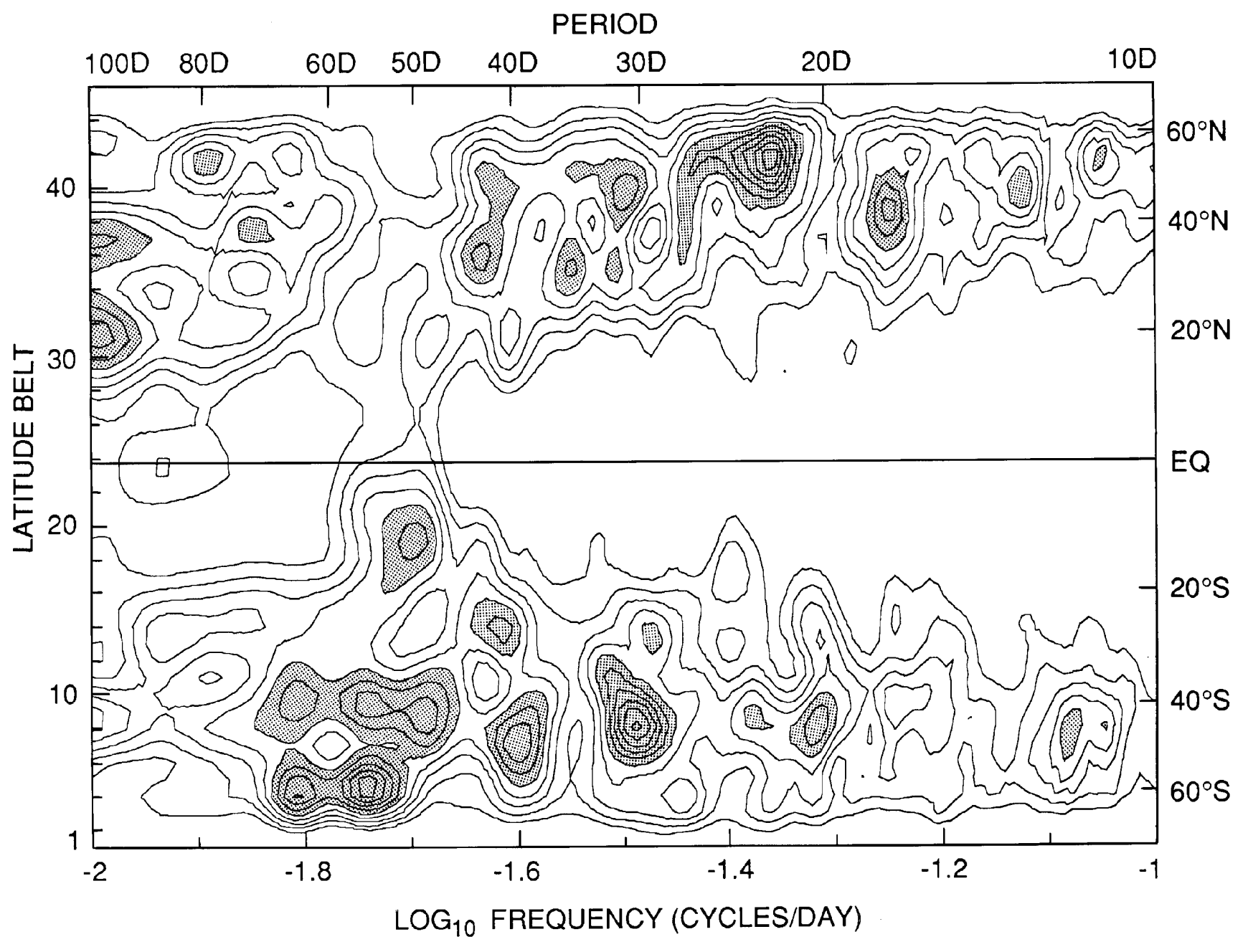


a) Bifurcation diagram

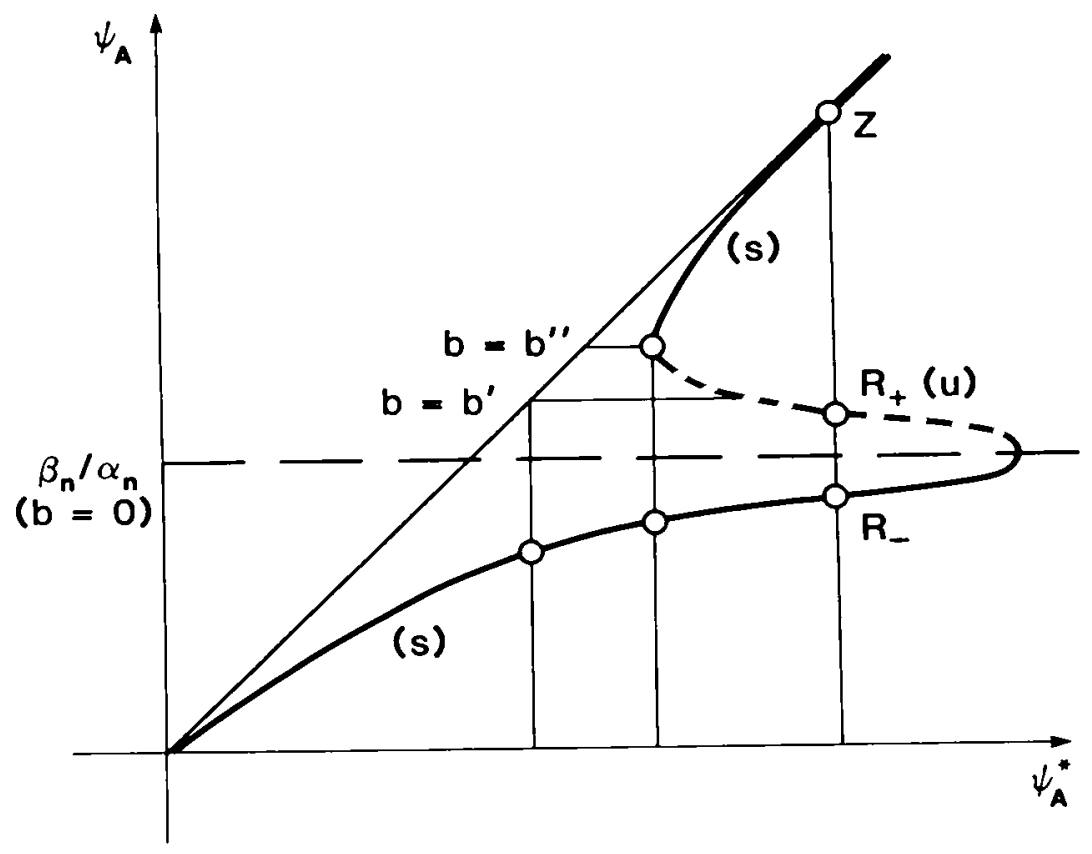

b) Flow patterns
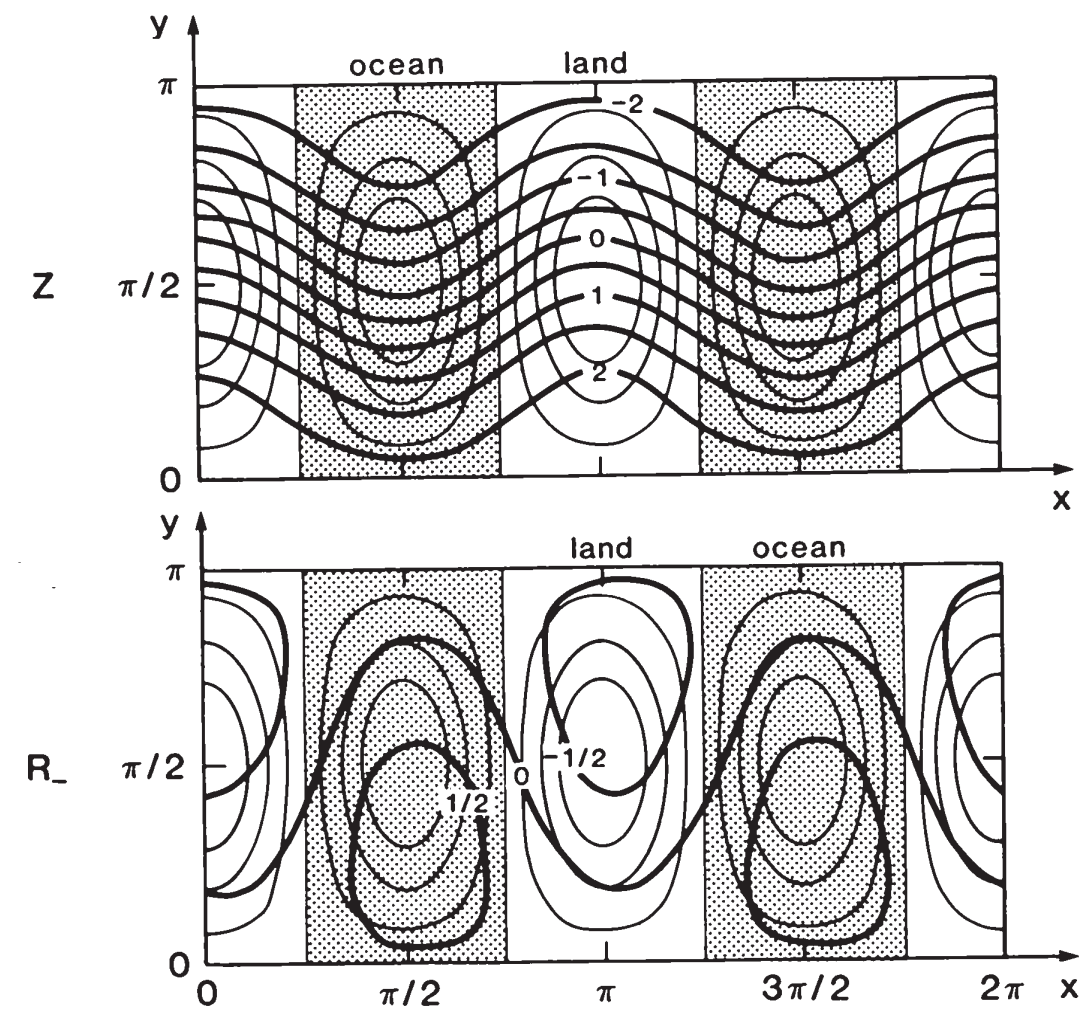


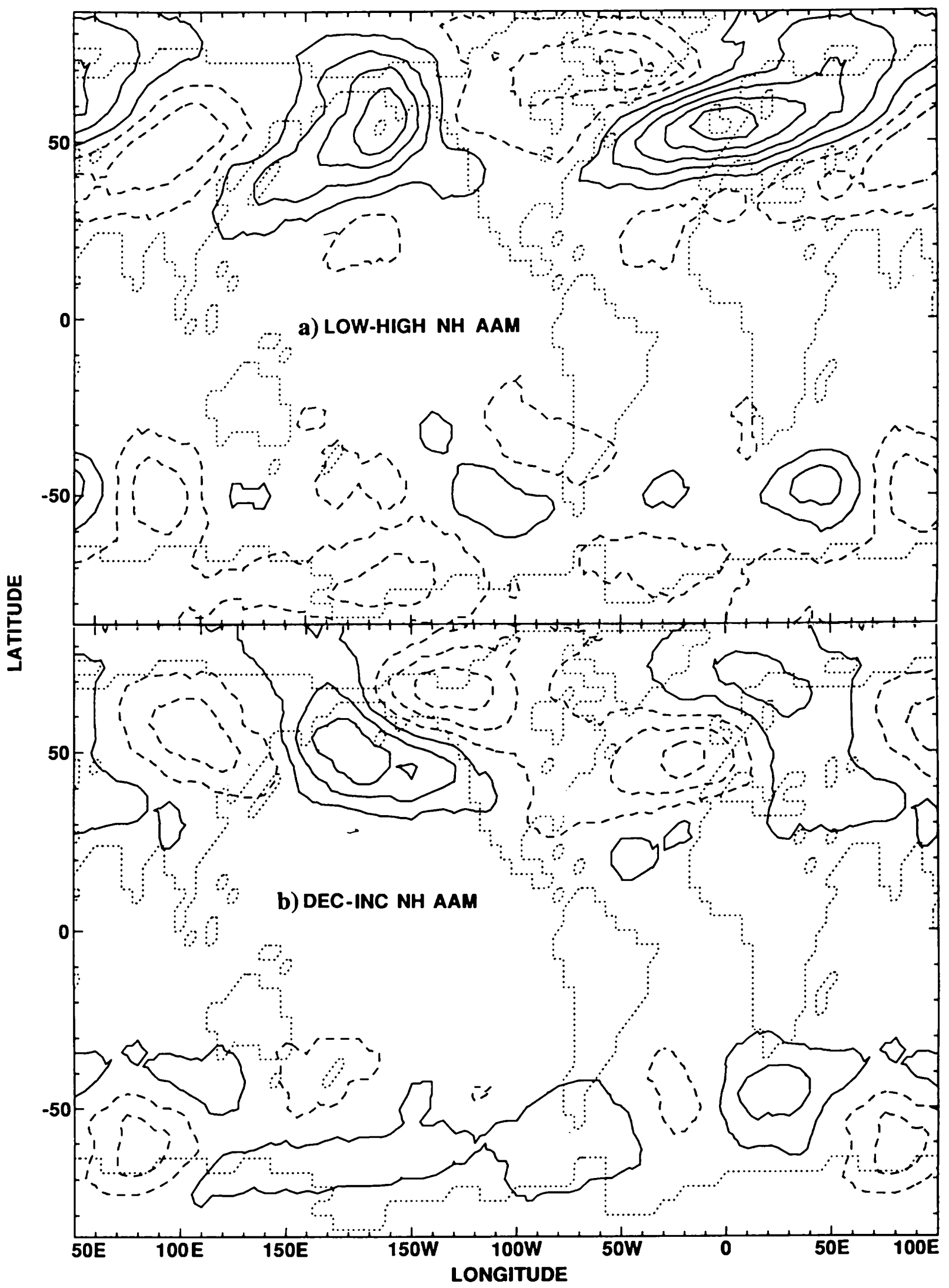




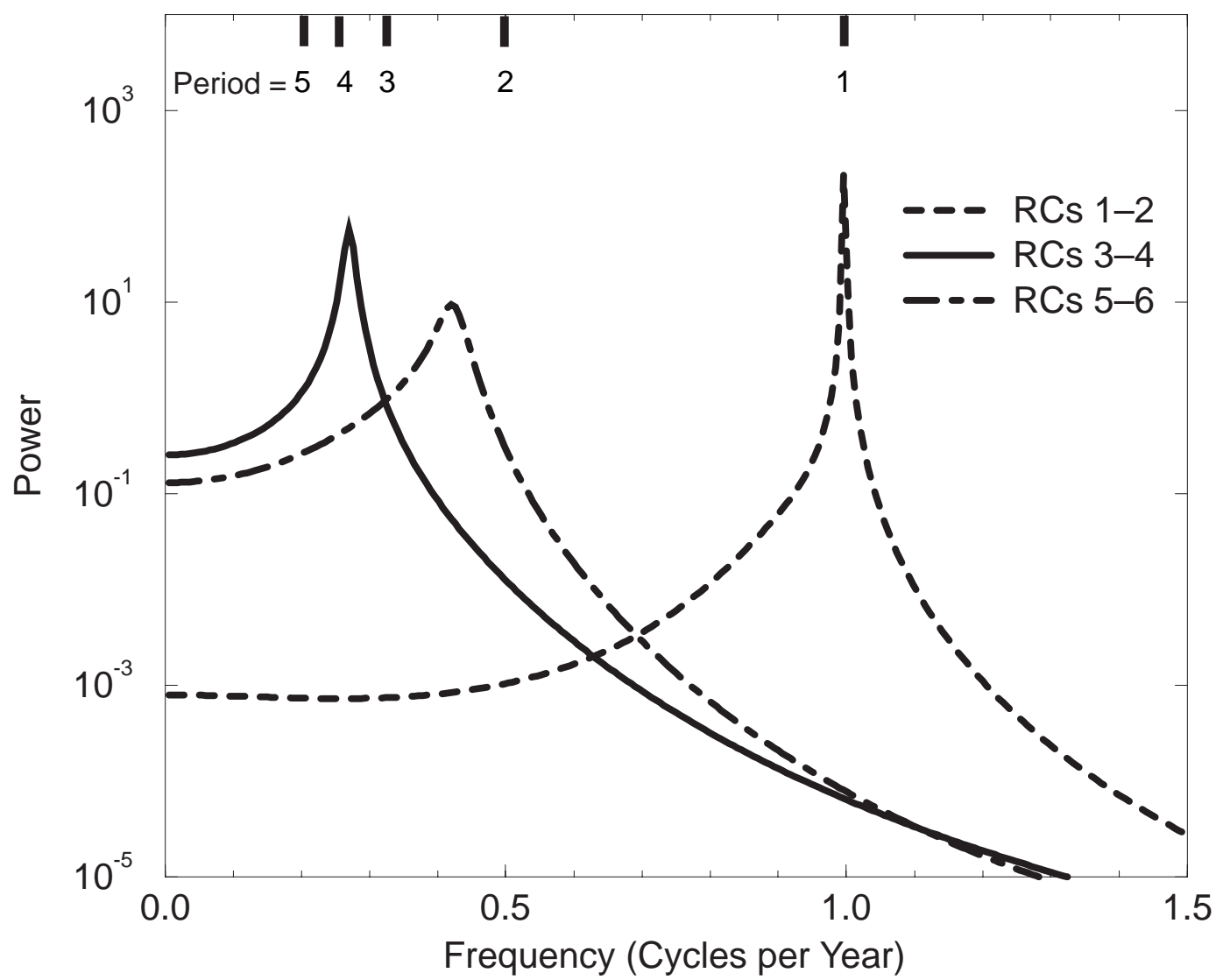


a) $\mu=\mu_{0}$

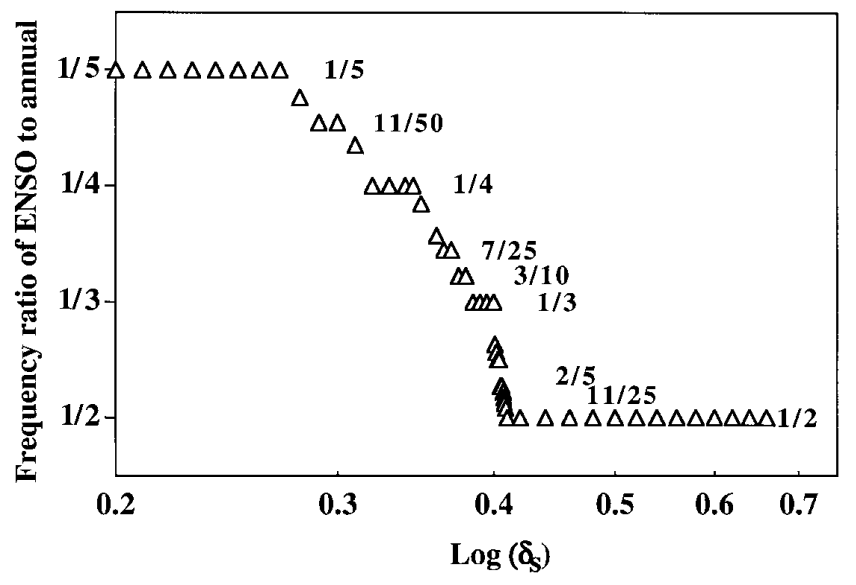

b) $\mu=1.1 \mu_{0}$

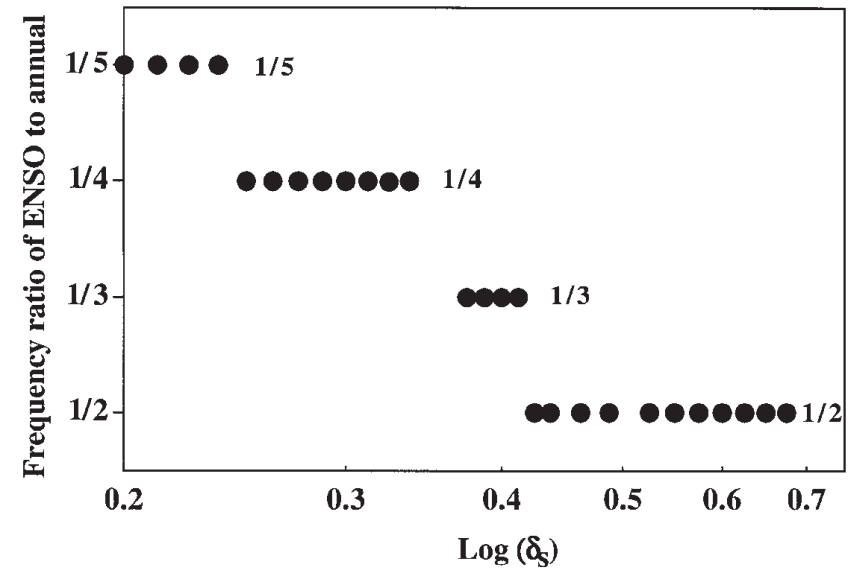


a) Decade I

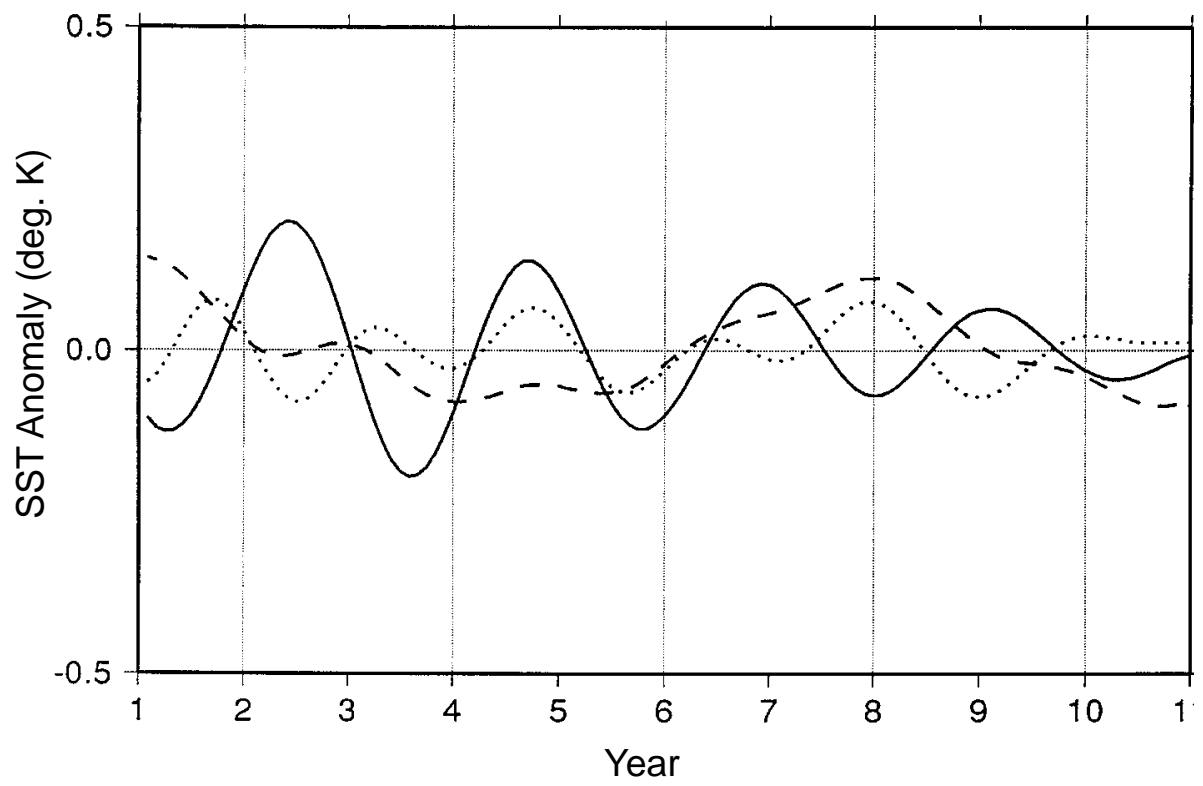

b) Decade II

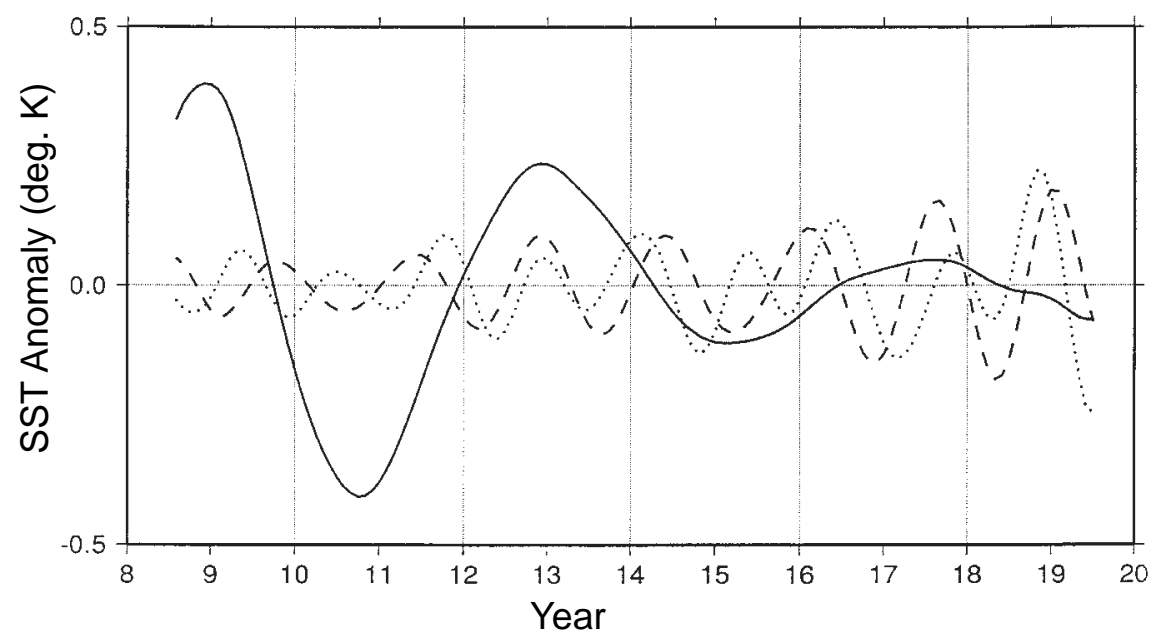


a) NASA Goddard model

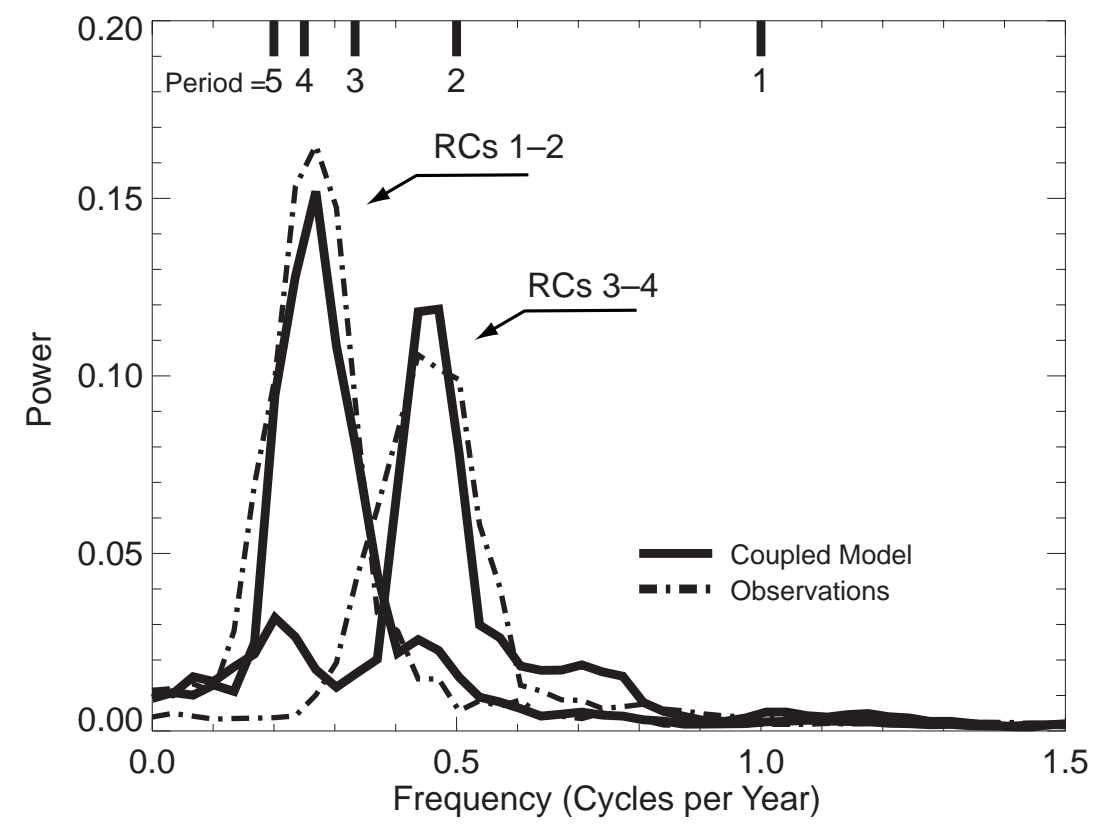

b) NCEP model

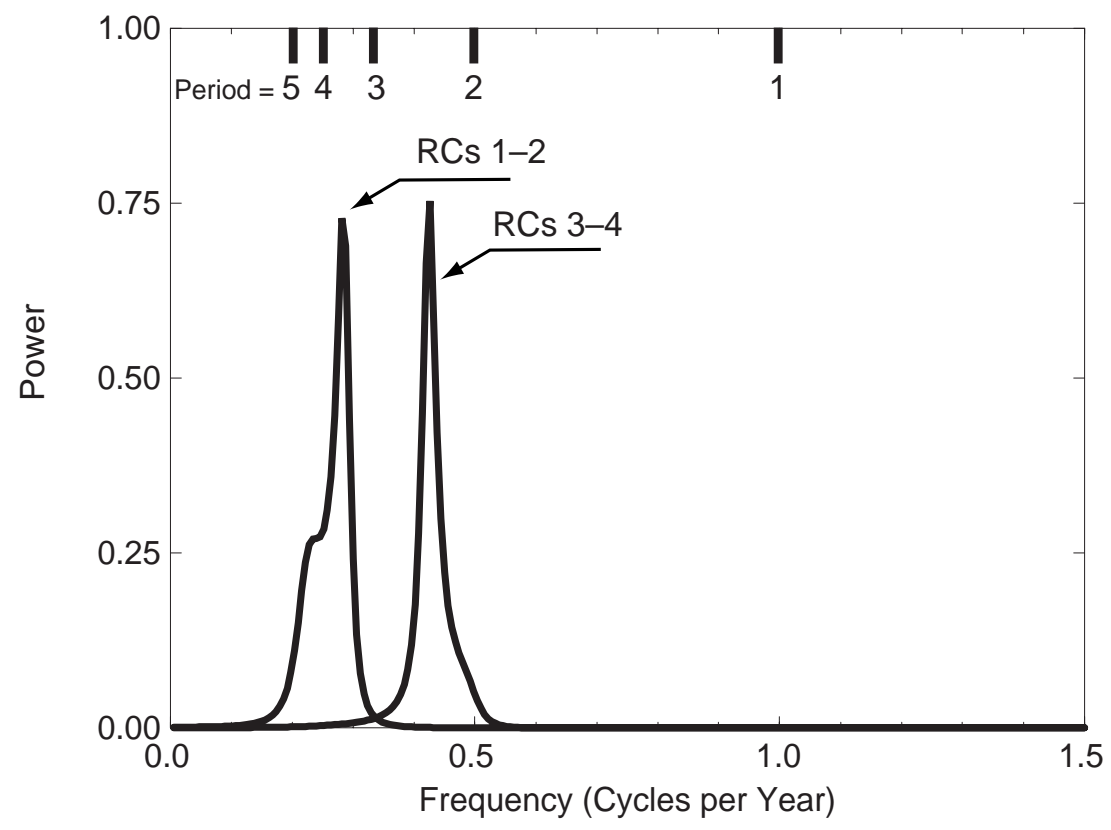


a) SST

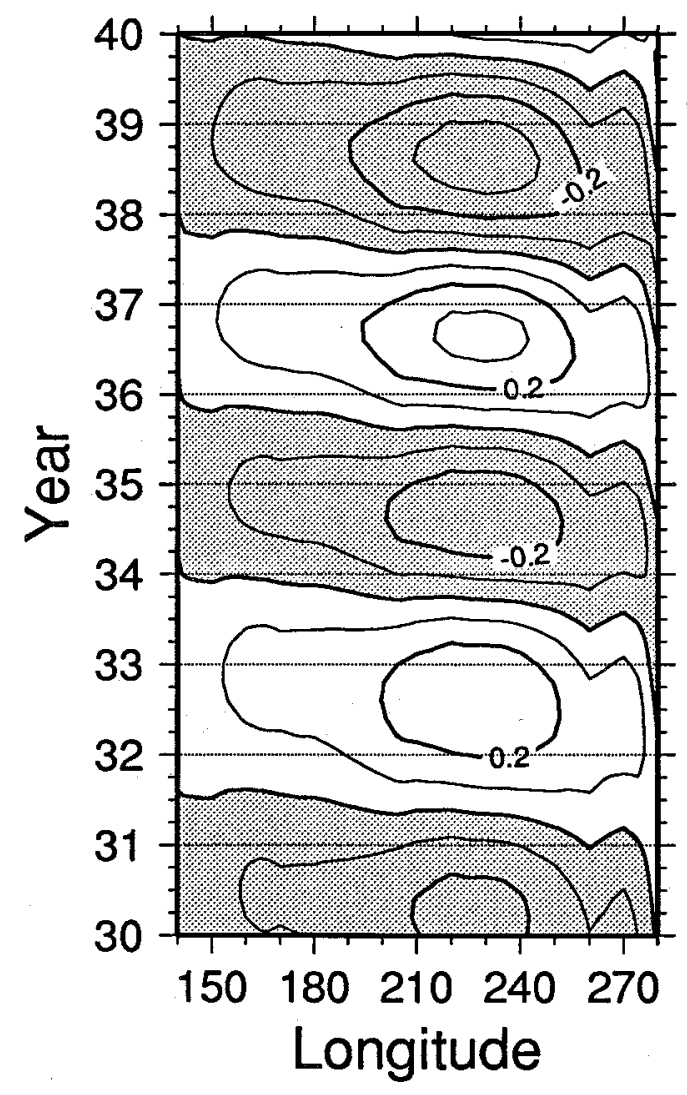

b) Wind stress

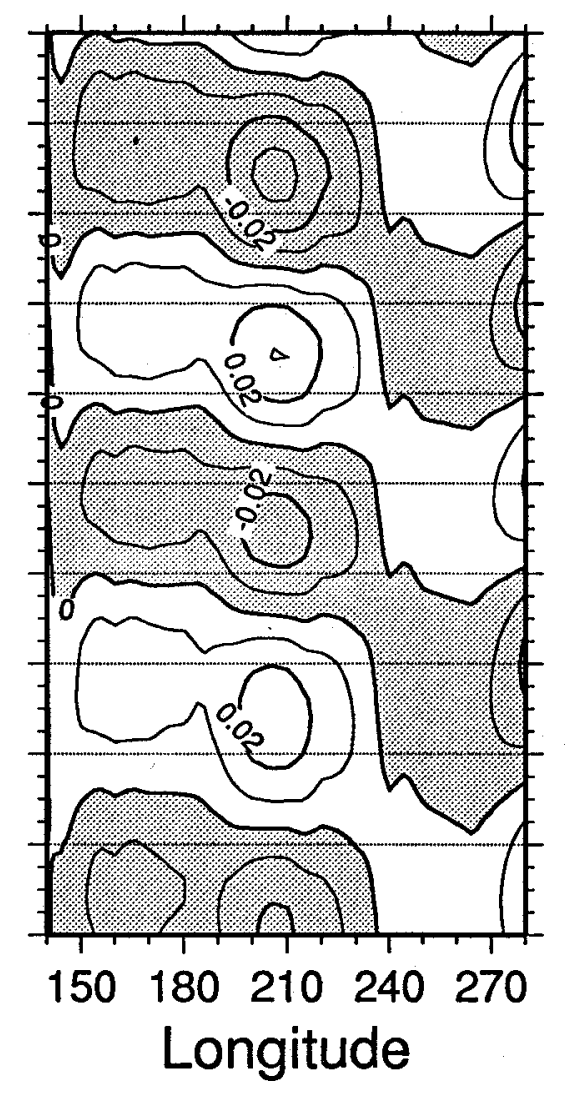

c) $20^{\circ} \mathrm{C}$ depth

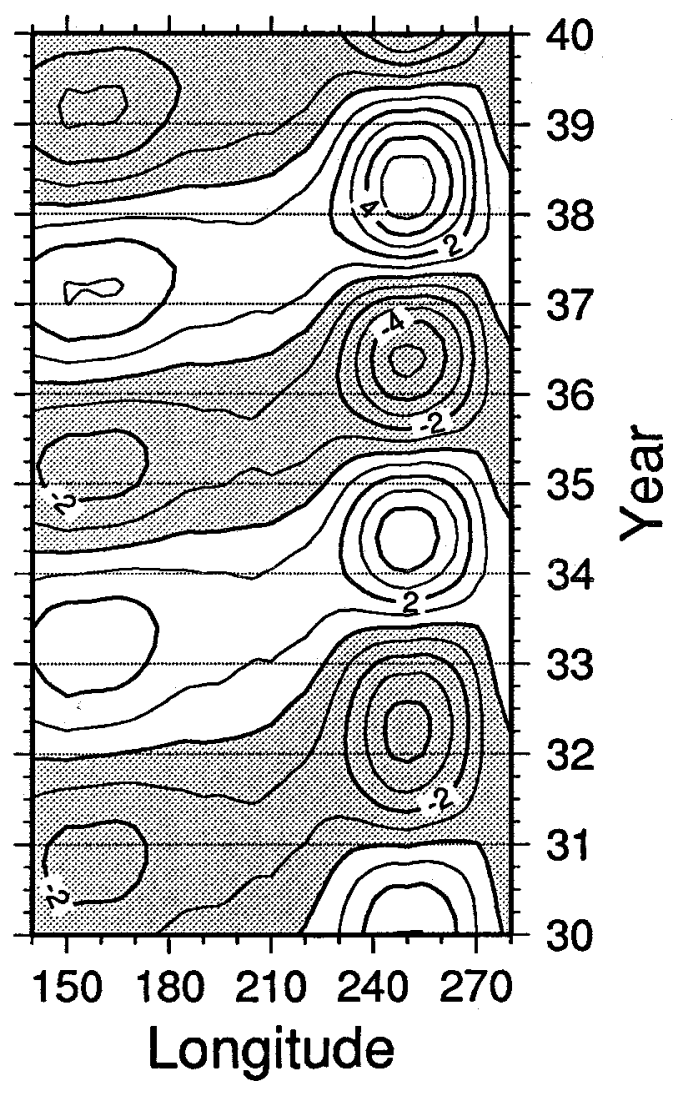




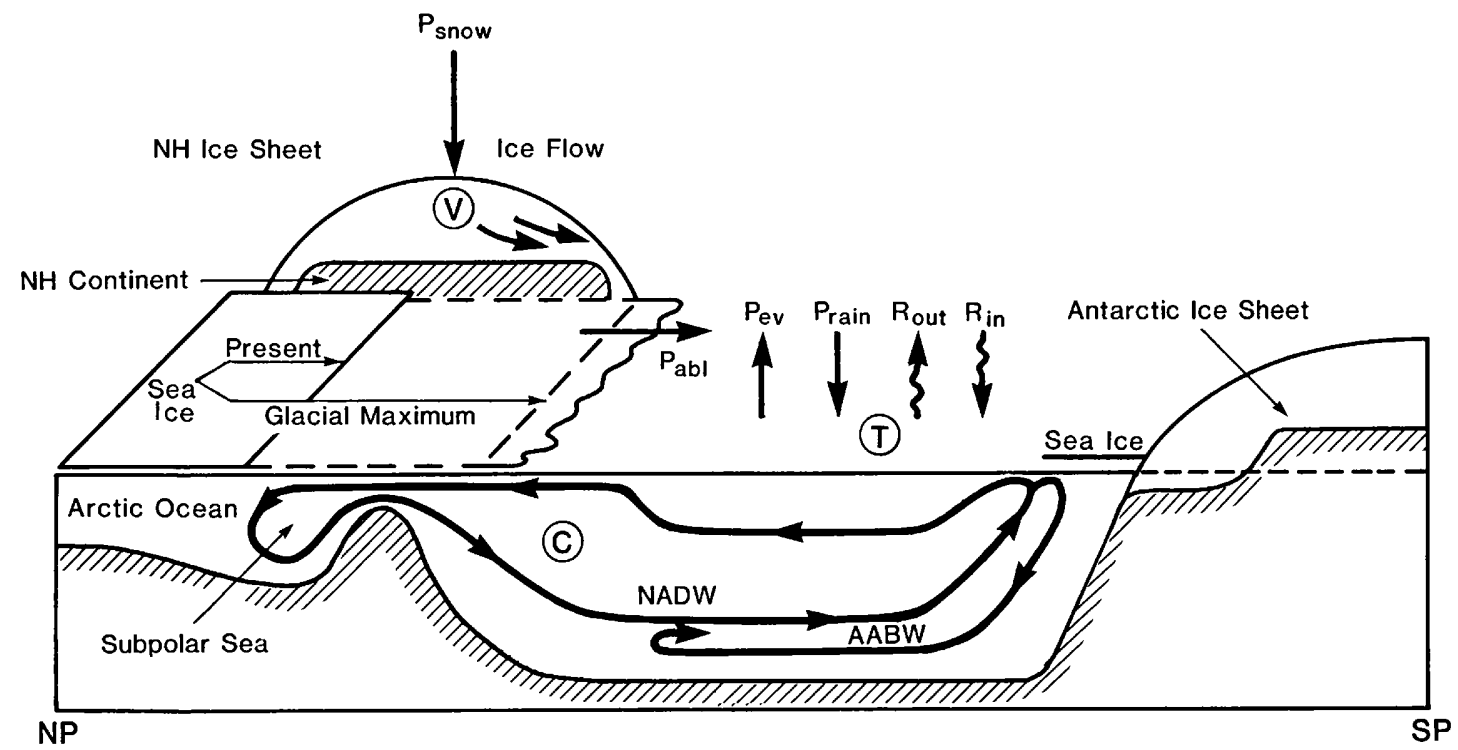


(a)

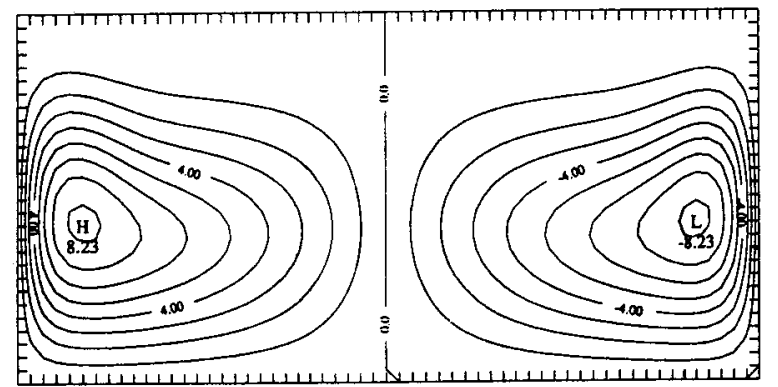

(b)

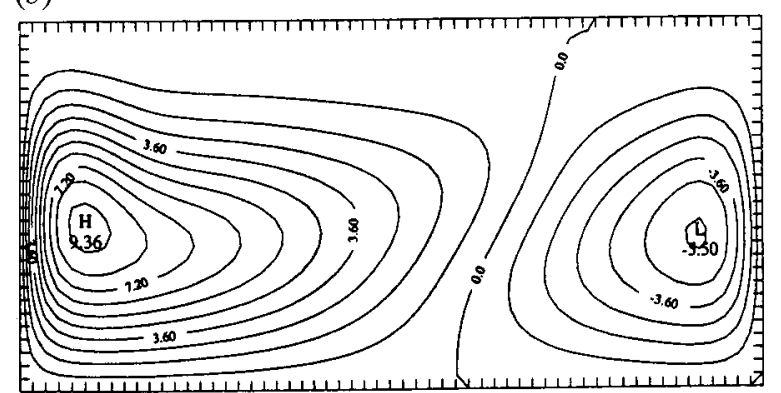

(c)

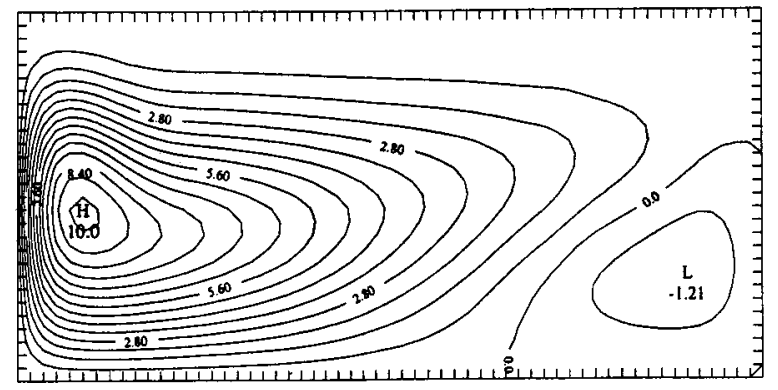


a) Regime diagram

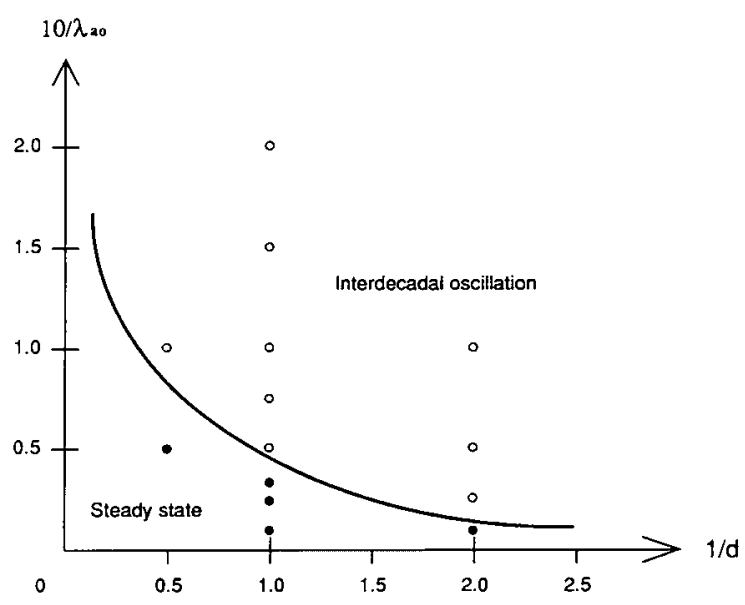

b) Bifurcation diagram

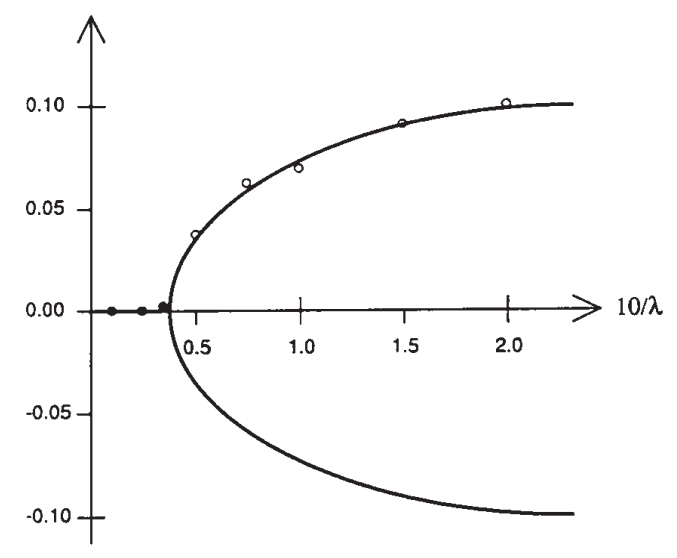

